\title{
The STAT7 Code for Statistical Propagation of Uncertainties In Steady-State Thermal Hydraulics Analysis of Plate-Fueled Reactors
}

Nuclear Science \& Engineering Division 


\begin{abstract}
About Argonne National Laboratory
Argonne is a U.S. Department of Energy laboratory managed by UChicago Argonne, LLC under contract DE-AC02-06CH11357. The Laboratory's main facility is outside Chicago, at 9700 South Cass Avenue, Argonne, Illinois 60439. For information about Argonne and its pioneering science and technology programs, see www.anl.gov.
\end{abstract}

\title{
DOCUMENT AVAILABILITY
}

Online Access: U.S. Department of Energy (DOE) reports produced after 1991 and a growing number of pre-1991 documents are available free at OSTI.GOV (http://www.osti.gov/), a service of the U.S. Dept. of Energy's Office of Scientific and Technical Information.

\author{
Reports not in digital format may be purchased by the public from the \\ National Technical Information Service (NTIS): \\ U.S. Department of Commerce \\ National Technical Information Service \\ 5301 Shawnee Rd \\ Alexandria, VA 22312 \\ www.ntis.gov \\ Phone: (800) 553-NTIS (6847) or (703) \\ 605-6000 Fax: (703) 605-6900 \\ Email: orders@ntis.gov
}

Reports not in digital format are available to DOE and DOE contractors from the Office of Scientific and Technical Information (OSTI):

U.S. Department of Energy

Office of Scientific and Technical Information

P.O. Box 62

Oak Ridge, TN 37831-0062

www.osti.gov

Phone: (865) 576-8401

Fax: (865) 576-5728

Email: reports@osti.gov

Disclaimer

\section{Disclaimer}

This report was prepared as an account of work sponsored by an agency of the United States Government. Neither the United States Government nor any agency thereof, nor UChicago Argonne, LLC, nor any of their employees or officers, makes any warranty, express or implied, or assumes any legal liability or responsibility for the accuracy, completeness, or usefulness of any information, apparatus, product, or process disclosed, or represents that its use would not infringe privately owned rights. Reference herein to any specific commercial product, process, or service by trade name, trademark, manufacturer, or otherwise, does not necessarily constitute or imply its endorsement, recommendation, or favoring by the United States Government or any agency thereof. The views and opinions of document authors expressed herein do not necessarily state or reflect those of the United States Government or any agency thereof, Argonne National Laboratory, or UChicago Argonne, LLC. 
ANL/RTR/TM-16/7 Rev. 1

\section{The STAT7 Code for Statistical Propagation of Uncertainties In Steady-State Thermal Hydraulics Analysis of Plate-Fueled Reactors}

prepared by

Son H. Pham ${ }^{1}$, Lin-wen $\mathrm{Hu}^{2}$, and Erik H. Wilson ${ }^{1}$

${ }^{1}$ Nuclear Science \& Engineering Division, Argonne National Laboratory

${ }^{2}$ Massachusetts Institute of Technology Nuclear Reactor Laboratory

July 2020 
(This page left intentionally blank) 


\section{ABSTRACT}

STAT7 was written to automate many of the steady-state thermal hydraulic safety calculations for the MIT research reactor, both for conversion of the reactor from highly enriched uranium fuel to lowenriched uranium fuel and for future fuel re-loads after the conversion. A Monte-Carlo statistical propagation approach is used to treat uncertainties in important parameters in the analysis. These safety calculations are ultimately intended to protect against high fuel plate temperatures due to critical heat flux or departure from nucleate boiling or onset of flow instability; but additional margin is obtained by basing the limiting safety settings on avoiding onset of nucleate boiling. STAT7 can simultaneously analyze all of the axial nodes of all of the fuel plates and all of the coolant channels for one stripe of a fuel element. The stripes run the length of the fuel, from the bottom to the top. Power splits are calculated for each axial node of each plate to determine how much of the power goes out each face of the plate. By running STAT7 multiple times, full core analysis can be performed by analyzing the margin to ONB for each axial node of each stripe of each plate of each element in the core. 


\section{Table of Contents}

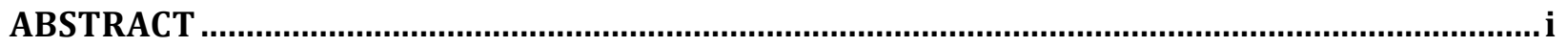

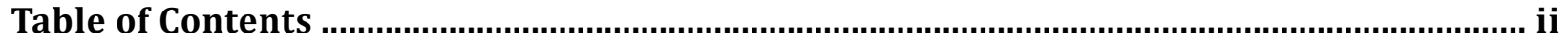

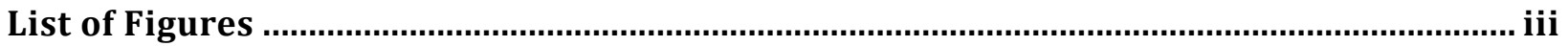

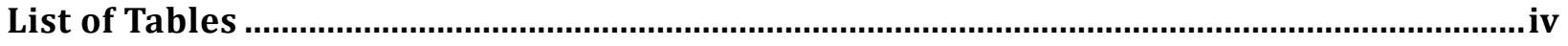

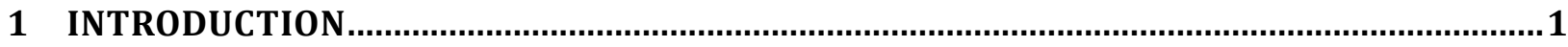

2 RECOMMENDATIONS FOR APPLICATION ........................................................................

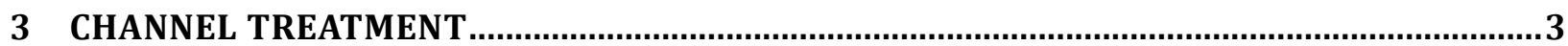

3.1 How Many Stripes are Necessary? ............................................................................................ 4

4 TREATMENT OF UNCERTAINTIES USING STATISTICAL APPROACH ....................................6

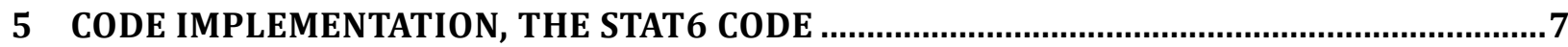

5.1 Thermal Hydraulics Calculations for a History …………..................................................................... 7

5.2 Carnavos Friction Factor for Fins ……….......................................................................................

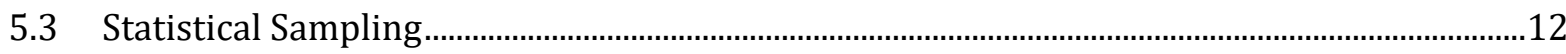

5.4 Comparison with Oracle-Crystal Ball Results ...........................................................................13

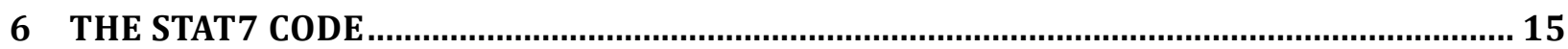

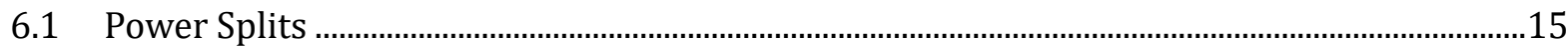

6.2 STAT7 Thermal Hydraulic Solution for a History …….................................................................15

6.3 Comparison of STAT7 Results with RELAP5 Results.......................................................................21

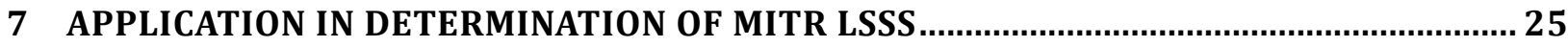

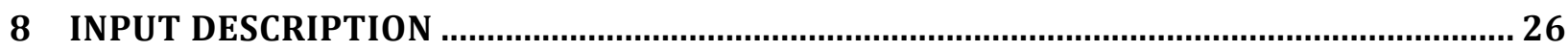

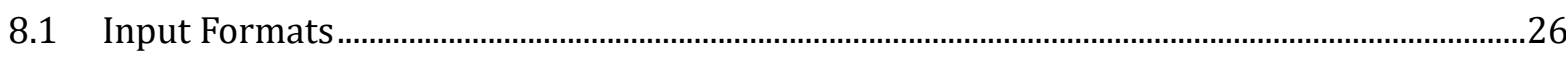

8.2 Input Description and Sample Values.............................................................................................26

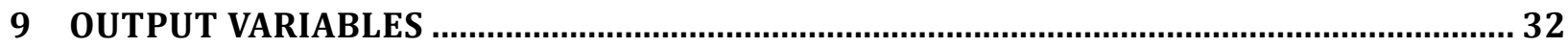

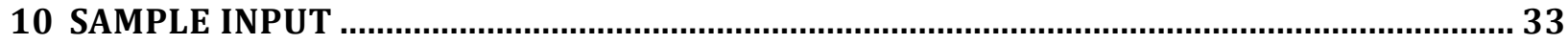

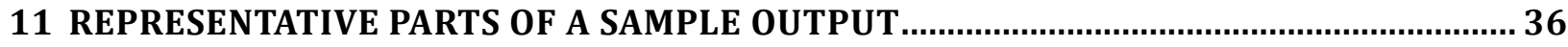

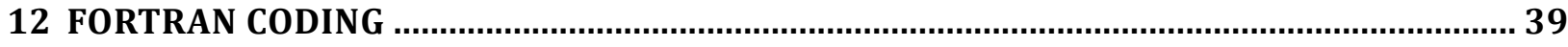

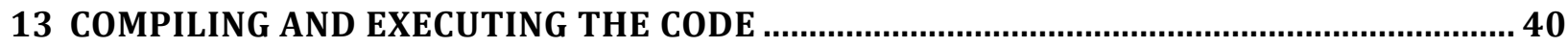

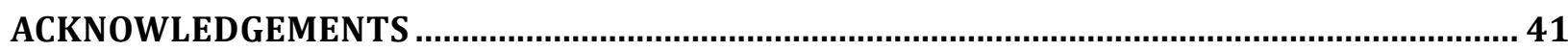

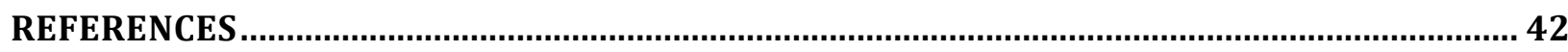

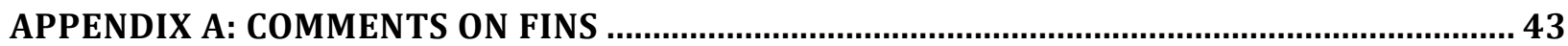

The STAT7 Code for Statistical Propagation of Uncertainties In 


\section{List of Figures}

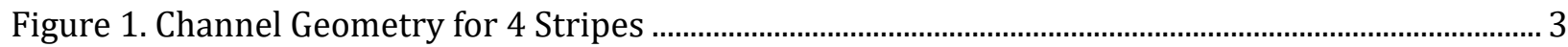

Figure 2. Multi-stripe RELAP5-3D Model ...................................................................................................... 4

Figure 3. Peak Clad Temperature results from RELAP5-3D for various stripe discretization of the fuel plate and the coolant channel, both with and without lateral heat conduction in the plate.................. 5

Figure 4. Comparison of STAT and Oracle-Crystal Ball Results .......................................................................13

Figure 5. Comparison of STAT7 and RELAP5 End Channel and Interior Channel Flow Rates..............22

Figure 6. Comparison Between STAT7 and RELAP5 Coolant Temperatures for an End Channel and the First Two Interior Channels ..................................................................................................................

Figure 7. Comparison Between STAT7 and RELAP5 Clad Surface Temperatures for an End Plate and the First Interior Plate

Figure 8. Comparison Between STAT7 and RELAP5 Peak Fuel Temperatures for an End Plate and the first Interior Plate

Figure 9. Comparison Between STAT7 and RELAP5 for Power Splits in an End Plate and the First Interior Plate 


\section{List of Tables}

Table 1. Parameters and Uncertainties. 6

Table 2. Geometry parameters in Carnavos correlation and derived values for an inner channel of an LEU fuel element 11

Table A.1. STAT7 Results for Various Fin Treatment Options... . .44 


\section{INTRODUCTION}

STAT7 was written to perform analysis of the steady state thermal hydraulic safety basis for MITR-II [Ref. 1], the MIT research reactor, but the code also may be applicable to other reactors with plate fuel. The conversion of MITR-II from highly enriched uranium (HEU) to low-enriched uranium (LEU) will involve a number of significant changes to the core, so a new steady-state and transient thermal hydraulic safety analyses is required. The number of required new safety analysis cases may be quite large. Optimization of the new fuel element design requires analysis of a large number of design options. Also, since there is great flexibility in MITR-II reactor fuel shuffling and reloading, it may be necessary to repeat at least part of the safety analysis in the future for every fuel reloading. The main goal is to provide a standardized and automated procedure and tool for the safety analysis. The work described in this report only addresses steady-state analysis as codified in STAT7. Transient analysis of accidents is also required, but the transient analysis is not within the scope of this code.

For steady-state operation safety limits analysis is performed in order to protect against critical heat flux (CHF) or departure from nucleate boiling (DNB). Since onset of flow instability (OFI) can lead to DNB, OFI is also to be avoided. In order to provide additional margin, the limiting safety system settings (LSSS) are based on avoiding onset of nucleate boiling (ONB). ONB will occur before either OFI or DNB.

The original thermal hydraulics approach was to calculate the margin to ONB for an interior channel at each axial node of the limiting fuel plate stripe in the core. The stripes run the length of the fuel, from the bottom of the fuel to the top of the fuel. For nominal dimensions before accounting for uncertainties, usually the stripe with the maximum stripe power will be the most limiting; but it may also be necessary to analyze the stripe containing the peak spot power to determine which stripe is limiting. Also, an end channel may be more limiting than the most limiting interior channel. The STAT software, development versions STAT5 and STAT6, has previously used the one interior channel approach, with additional features in each successive version including in STAT6 the ability to model an end channel. STAT7 added the capability to analyze one stripe for each plate and each coolant channel of one element, including the end channels. With STAT7, the steady-state thermal hydraulics calculations have been automated to the point that the current practice is to make multiple STAT7 runs to calculate the margin to ONB for each axial node of each stripe of each plate of each element in the core. 


\section{RECOMMENDATIONS FOR APPLICATION}

It has been noted that STAT7 cannot predict flow distribution correctly if the model involves both fins and bypass specifications. Therefore, the users must avoid this situation. Additionally, the users should consider the following points:

- The number of axial nodes should be large enough (ten or more) to make a valid ONB margin prediction.

- The output of Reynolds number should be used to check if the problem is within the applicable range of the thermal hydraulics correlations implemented in the software.

- The user should run the code using different seeds (isd1 and isd2) and different number of histories (nbatch and nsmpl) to confirm that the results obtained from run to run stay within expected tolerances.

- The fitted functions used to generate the coolant properties have only been checked for the temperature range of $10<\mathrm{T}<95^{\circ} \mathrm{C}$ and pressure range of $0.9<\mathrm{P}<1.5 \mathrm{bar}$.

- For the input parameters that are not involved in the statistical sampling process, the users should evaluate the continuing applicability of the assumed values (e.g. flow distribution). 


\section{CHANNEL TREATMENT}

Figure 1 illustrates a cross section of the channel geometry used for thermal hydraulics calculations. A number of axial nodes are modeled in this manner in the vertical direction.

Both interior channels and end channels must be considered. A simple interior 'half-channel' models the middle of the fuel to the middle of the adjacent interior coolant channel. There are a number of possible end channel geometries. An end channel models the region from the middle of the fuel of an end plate, including the whole end coolant channel, to the surface of the side plate of an adjacent assembly. This effectively models a coolant channel heated on one side but with wall friction on both sides. Variations on this type of end channel include end coolant channels that face the core housing, the inner hex or an arm. Qualitatively these situations are similar, but the end coolant gap size depends on what the end channel is facing. Another possibility is that the end coolant channel of one element could face the end coolant channel of another element, creating one larger coolant channel heated on both sides.

Originally the calculations done for this work included only half of one fuel plate and half of an adjacent coolant channel for an interior channel or an end channel heated on both sides. The entire adjacent coolant channel was used for an end channel facing an unheated surface. Only a minor modification to the computational procedure was required to add the option to treat a coolant channel heated on both sides. With this option an interior channel was modeled from the middle of plate 1 to the middle of plate 2, as shown in Figure 1. Also, an end channel heated on both sides can be treated more accurately. The treatment has been extended to simultaneously treat every plate and every coolant channel in one stripe of an element.

In this channel treatment, the width of a sub-channel is equal to the width of a single stripe in the fuel. The non-fueled sides of the plate and the coolant in contact with the non-fueled sides are ignored. Lateral coolant mixing between stripes is ignored. Also lateral conduction between stripes in the fuel and clad is ignored.

NOTE: not to scale

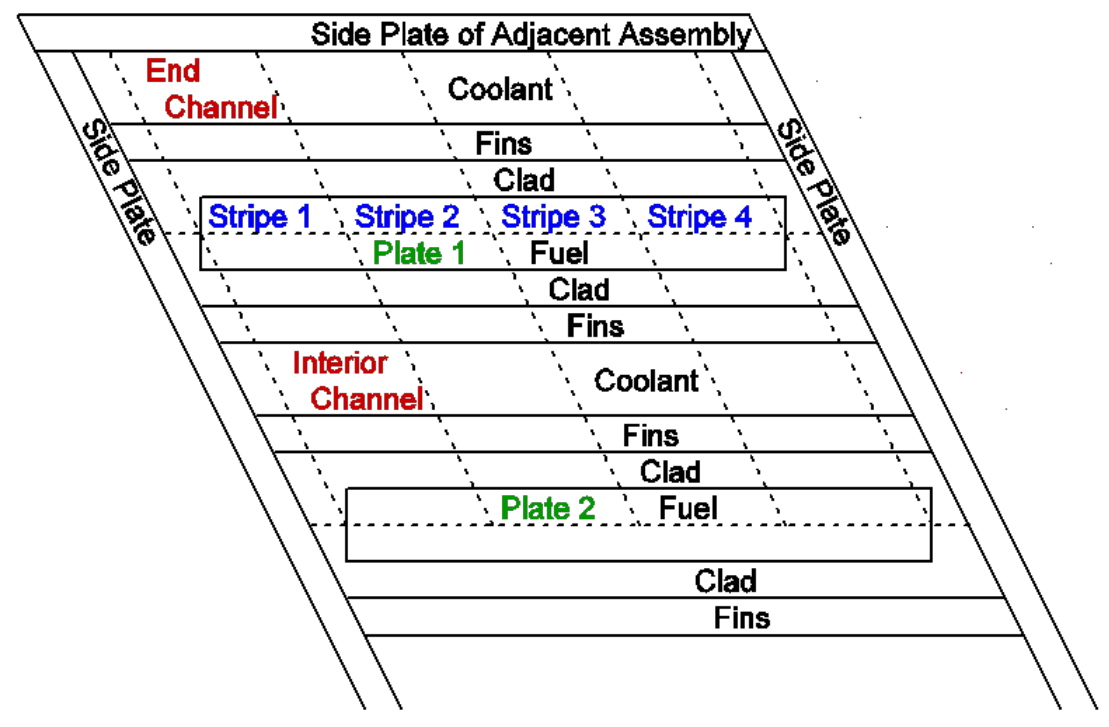

Figure 1. Channel Geometry for 4 Stripes

The STAT7 Code for Statistical Propagation of Uncertainties In Steady-State Thermal Hydraulics Analysis of Plate-Fueled Reactors 


\subsection{How Many Stripes are Necessary?}

One of the issues that can be addressed by models implemented in this software is the question of how many lateral stripes are necessary to obtain an accurate or conservative evaluation of peak clad temperatures. The plate power profiles for MITR-II are peaked fairly sharply at the sides of the fuel near the side plate since beyond the edges of the fuel there is less fuel self-shielding of the thermal neutron flux, which causes most of the fissions. Absorption and fission in the fuel reduces the thermal neutron flux in the fuel. The fuel is a source for high energy fission neutrons but a sink for thermal neutrons.

Lateral thermal conduction in the fuel and the clad can reduce the peaking in lateral temperature profiles. To investigate this situation a multi-stripe model, as shown in Figure 2, was set up using RELAP5-3D [Ref. 2]. Eighteen channels were used to model the region from the middle of the end plate fuel to the surface of the side plate of the adjacent assembly. Channels 1 to 16 model 16 stripes in the fueled part of the plate. Channels 0 and 17 model the plate and coolant between the sides of the fuel foil and the side plates. Axial power profiles for a peak power LEU case were obtained with the MCNP code for each of the 16 fueled stripes. A number of variations on this model were run, with and without lateral conduction between adjacent channels or axial conduction in the plate. Also, adjacent fueled channels were combined to make 4 channels or 8 channels in the fuel for additional cases. In all cases coolant mixing or direct lateral heat transfer between coolant channels was ignored.

RELAP5-3D is mainly a transient code. It does not provide a direct steady-state solution for this type of case. Therefore, a null transient, starting from uniform temperatures everywhere, was run. For the null transient the power levels, coolant inlet temperature, and total coolant flow rate were held constant; and the transient was run until the temperatures reached steady-state.

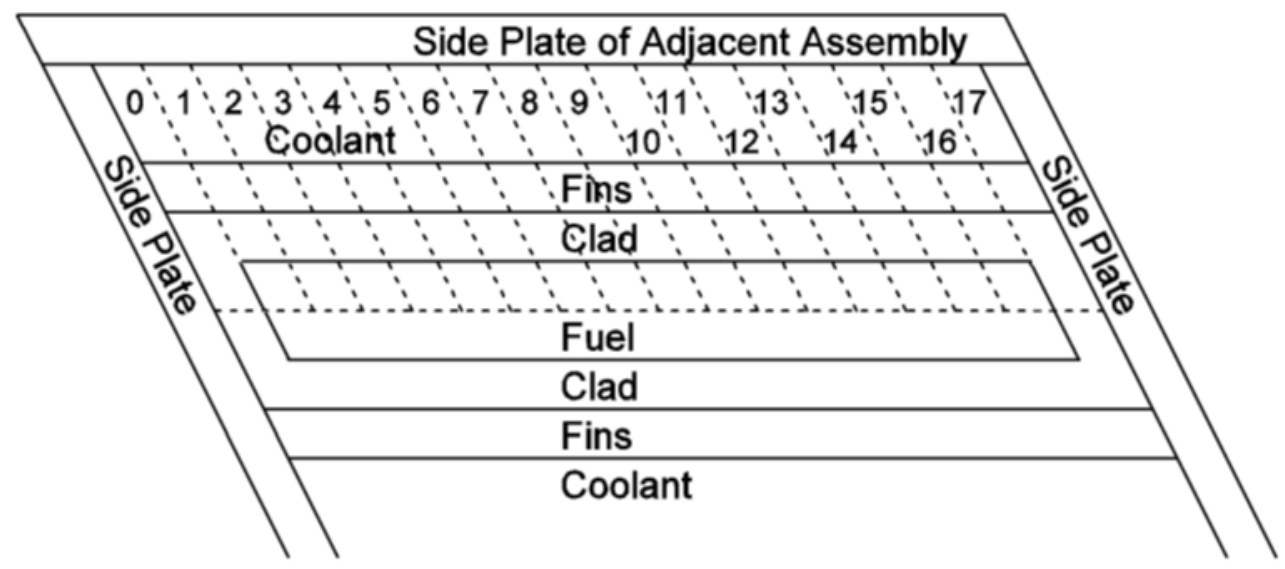

Figure 2. Multi-stripe RELAP5-3D Model

Results from these RELAP5-3D multi-stripe runs are shown in Figure 3. Axial conduction makes no significant change in the peak clad temperatures, so no axial conduction cases are shown in this figure. With no lateral conduction the peak clad temperature rise from the inlet temperature is proportional to the stripe power, so the no lateral conduction results indicate the lateral power peaking. Lateral conduction significantly reduces the peak clad temperature. The peak clad temperature for 4 stripes and no lateral conduction is higher than that for 8 or 16 stripes and with 
lateral conduction. Therefore, in the case of MITR fuel plates, 4 stripes are conservative for a multistripe steady-state calculation with no lateral conduction.

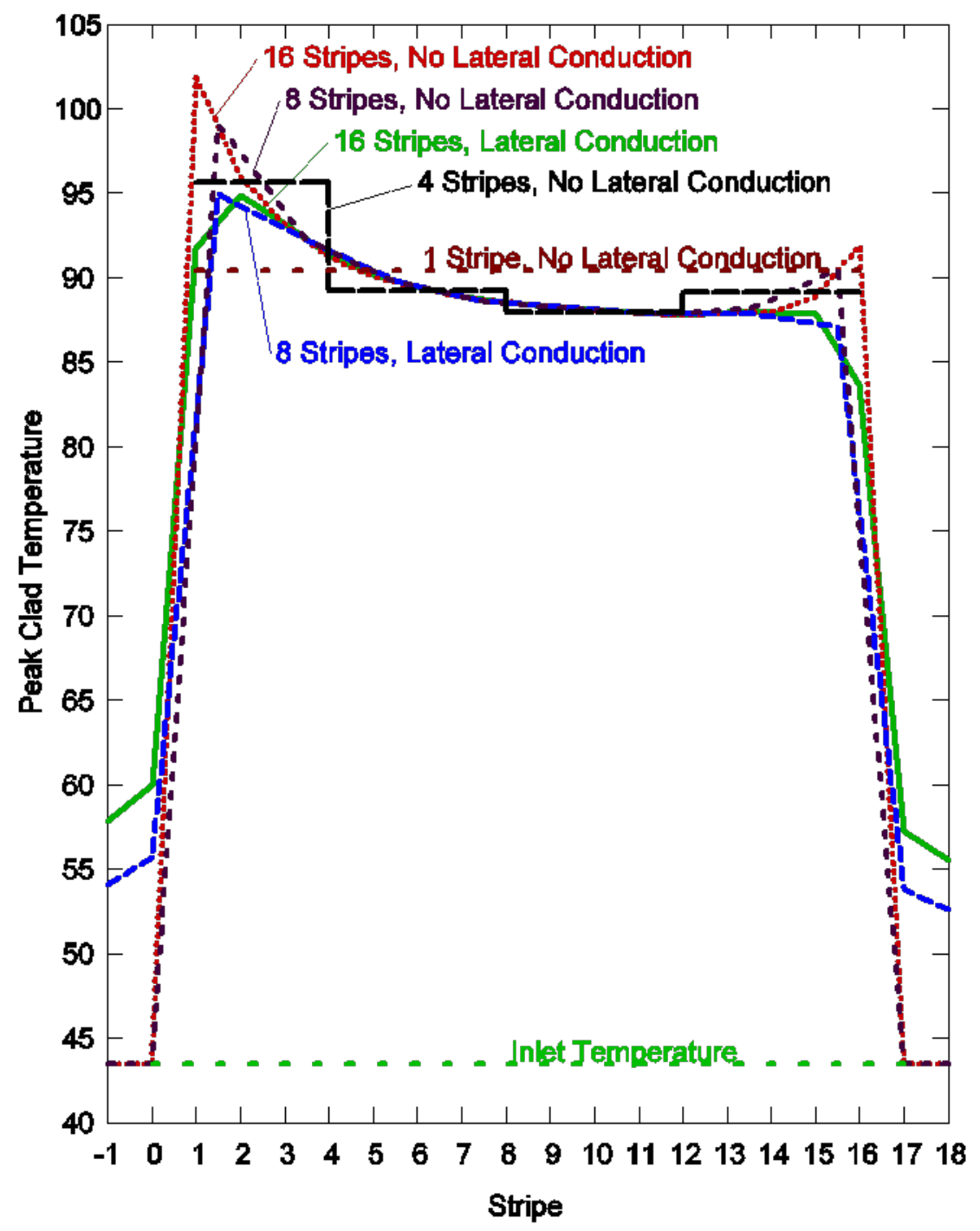

Figure 3. Peak Clad Temperature results from RELAP5-3D for various stripe discretization of the fuel plate and the coolant channel, both with and without lateral heat conduction in the plate. 


\section{TREATMENT OF UNCERTAINTIES USING STATISTICAL APPROACH}

For the thermal hydraulics calculations to support the LSSS settings, uncertainties in important parameters are treated with a Monte-Carlo statistical propagation approach. The statistical propagation approach for MITR-II was initially implemented by L-W Hu and K-Y Chang [Ref. 3] using the Oracle spreadsheet program with the Crystal Ball plug-in. For a given nominal (measured) value of the total reactor power, a large number of histories are run. For each history the values of important parameters are set based on random sampling from the uncertainty distributions for respective parameters. Then a steady-state thermal hydraulics calculation is done for the channel. If the clad surface temperature exceeds the ONB limit at any axial node, then the ONB count is increased by one. Note that for a given history the result used in the statistical analysis is either a 0 (no ONB anywhere) or a 1 (ONB at one or more axial nodes of one or more plates). The amount by which ONB is exceeded in a history is not used. The ONB probability for the specified nominal operating parameters is then given by the ratio of the number of ONB histories to the total number of histories. An iteration process is used to repeat the calculations for additional nominal reactor powers until the power at which a specific probability of ONB occurring is predicted. During the reactor power iteration the nominal values of all other parameters are held constant. Currently the specified probability of ONB occurring is 0.00135 , which corresponds to a 3-sigma confidence level of 99.865\%.

The parameters whose uncertainties are treated with the statistical propagation approach are listed in Table 1. The uncertainty values in this table are examples that have been used or that are currently being used. The uncertainties listed in this table are treated as 3-sigma values, and normal distributions are assumed for the uncertainties.

Table 1. Parameters and Uncertainties

\begin{tabular}{|l|l|}
\hline Parameter & 3-sigma Uncertainty (\%) \\
\hline Reactor power & 5 \\
\hline Local power & 14.1 \\
\hline Pump flow & 5 \\
\hline Fin-to-fin interior channel coolant gap size & 6.9 \\
\hline Film heat transfer coefficient & 20 \\
\hline
\end{tabular}




\section{CODE IMPLEMENTATION, THE STAT6 CODE}

A small FORTRAN program, the STAT code, was written to implement and automate the thermal hydraulics calculations for the statistical propagation method for MITR-II. The STAT code is not integrated with neutronics. One neutronics calculation for each core configuration of interest must be made to generate for the whole core stripe powers and axial power shapes used in the Stat thermal hydraulic analysis.

A STAT6 case calculates the nominal reactor power level at which a specified ONB probability occurs for one channel representing a stripe in one element. The input for a STAT6 case includes design information, plus axial fuel plate power shapes for a stripe in one or two plates and the fraction of the total reactor power in the stripe for the plate or plates, plus the standard deviations in the probability distributions for the parameters listed in Table 1. Also inputs are the ONB probability level, the number of Monte-Carlo histories for each reactor power iteration, and the first value of the nominal power for the power iteration.

The output from a STAT6 case is mainly the nominal reactor power level at which the specified ONB probability occurs. Also output is some statistical information on the standard deviation of the ONB probability for the final power iteration. Thermal hydraulics results for some samples can also be outputted.

\subsection{Thermal Hydraulics Calculations for a History}

At the start of the thermal hydraulics calculations for a history, the nominal reactor power, $\mathrm{P}_{\mathrm{r}}$, is known from the power iteration. The coolant outlet temperature, $\mathrm{T}_{\mathrm{x}}$, and the nominal pump flow, $\mathrm{W}_{\mathrm{p}}$ are set by the input. After some initialization, the calculations for a history go through the following steps in order. Note that there is no over-all iteration in the thermal hydraulics calculations for a history, although there are two-step iterations within some individual steps to make temperaturedependent coolant properties consistent with the coolant temperatures.

\section{Nominal Stripe Power and Flow}

The nominal hot stripe power, $\mathrm{P}_{\mathrm{s}}$, is calculated as:

$$
\mathrm{P}_{\mathrm{s}}=\mathrm{P}_{\mathrm{r}} \mathrm{f}_{\mathrm{c}} \mathrm{f}_{\mathrm{s}} /\left(\mathrm{N}_{\mathrm{e}} \mathrm{N}_{\mathrm{p}} \mathrm{N}_{\mathrm{s}}\right)
$$

Where

$\mathrm{P}_{\mathrm{r}}=$ nominal core power

$\mathrm{f}_{\mathrm{c}}=$ the fraction of the fission power deposited in the core region

$\mathrm{f}_{\mathrm{s}}=$ hot stripe power/core average stripe power

$\mathrm{N}_{\mathrm{e}}=$ number of elements

$\mathrm{N}_{\mathrm{p}}=$ number of plates per element

$\mathrm{N}_{\mathrm{s}}=$ number of stripes/plate

If the 2-plate option is used, then the nominal stripe 2 power, $P_{\mathrm{s} 2}$, is calculated the same way using $\mathrm{f}_{\mathrm{s} 2}$, the stripe 2 power/core average power, instead of $\mathrm{f}_{\mathrm{s}}$.

The nominal interior channel stripe coolant flow, $\mathrm{W}_{\mathrm{i}}$, is calculated as

$$
W_{i}=W_{p} f_{f} d_{f} f_{i n} f_{s f} /\left(N_{e} N_{p} N_{s}\right)
$$


Where

$\mathrm{W}_{\mathrm{p}}=$ Nominal pump flow

$\mathrm{f}_{\mathrm{f}}=$ Coolant core flow fraction. This accounts for bypass flow.

$\mathrm{d}_{\mathrm{f}}=$ Plenum flow disparity factor; accounts for element to element flow variation

$f_{\text {in }}=$ Ratio of the average interior channel flow to the average channel flow. This accounts for the average end channel flow being different from the average interior channel flow.

$\mathrm{f}_{\mathrm{sf}}=$ Fraction of the coolant channel flow in the stripe region. This accounts for neglecting the flow between the side plate and the edge of the fuel foil.

This section is skipped except for the first history of each reactor power iteration, since the results are the same for later histories.

\section{Reactor Power and Pump Flow}

The statistical sampling value, $\left[P_{r}\right]$, for the reactor power is randomly sampled from the nominal value, $\mathrm{P}_{\mathrm{r}}$, and the standard deviation. Also, the sample value, $\left[W_{p}\right]$, for the pump flow is randomly sampled from the nominal value and the standard deviation.

\section{Coolant Inlet Temperature}

The coolant inlet temperature, $\mathrm{T}_{\mathrm{in}}$, is obtained from

$$
\mathrm{T}_{\text {in }}=\mathrm{T}_{\mathrm{x}}-\left[P_{r}\right] \mathrm{f}_{\mathrm{c}} /\left(\left[W_{p}\right] \mathrm{C}_{\mathrm{p}}\right)
$$

where $\mathrm{f}_{\mathrm{c}}$ is the fraction of the power deposited in the core region. $\mathrm{C}_{\mathrm{p}}$ is the heat capacity of the water. $\mathrm{T}_{\mathrm{x}}$ is the outlet temperature. Note that all coolant properties are calculated by fitted functions which were established using NIST fluid database [Ref. 4].

A two-step iteration is used to obtain some consistency between the temperature-dependent value of $\mathrm{C}_{\mathrm{p}}$ and the average core coolant temperature. In the first step, $\mathrm{C}_{\mathrm{p}}$ is calculated using $\mathrm{T}_{\mathrm{x}}$ as the coolant temperature. In the second step Equation 3 is repeated with the temperature used for $C_{p}$ based on the average of $\mathrm{T}_{\mathrm{x}}$ and the first step value for $\mathrm{T}_{\mathrm{in}}$.

\section{Hot Stripe Gap Size, Coolant Flow Area and Hydraulic Diameter}

The statistical sampling value for the hot stripe gap size, $[G]$, is obtained from the nominal value, $\mathrm{G}$, and the standard deviation. The coolant flow area, $\mathrm{A}_{G}$, and hydraulic diameter, $\mathrm{D}_{\mathrm{h} G}$, for this gap size are then calculated.

\section{Hot Stripe Coolant Flow Rate}

The coolant channel friction factor, $\mathrm{f}$, is obtained from

$$
\mathrm{f}=\mathrm{a}_{\mathrm{fr}} \operatorname{Re} \mathrm{bfr}^{\mathrm{fr}}
$$

Typically $\mathrm{a}_{\mathrm{fr}}=0.184$, and $\mathrm{bfr}=-0.2$ [Ref. 5], but the user can specify different values. If the core channel pressure drop is mainly due to friction with a turbulent friction factor proportional to the Reynolds number raised to the -0.20 power, then a channel flow rate will be proportional to the flow 
area times the hydraulic diameter to the 0.667 power. Thus, the hot stripe coolant flow rate, $\mathrm{W}_{\mathrm{s}}$, is obtained from

$$
\mathrm{W}_{\mathrm{s}}=\mathrm{W}_{\mathrm{i}}\left(\left[W_{p}\right] / \mathrm{W}_{\mathrm{p}}\right)\left(\mathrm{A}_{G} / \mathrm{A}_{0}\right)\left(\mathrm{D}_{\mathrm{h} G} / \mathrm{D}_{\mathrm{h} 0}\right)^{0.667}
$$

Where

$\mathrm{A}_{0}=$ nominal interior channel stripe flow area

$\mathrm{D}_{\mathrm{h} 0}=$ nominal interior channel stripe hydraulic diameter

Note that although Equation (2) applies to the nominal interior channel, Equation (4) can be used for either an interior channel or an end channel if the appropriate values are used for $\mathrm{A}_{G}$ and $\mathrm{D}_{\mathrm{h} G \text {. Also }}$ note that if bfr is not equal to -0.20 , then in Equation $4,0.667$ is replaced by $D_{\text {hrat }}$ given by

$$
D_{\text {hrat }}=(1-b f r) /(2+b f r)
$$

\section{Hot Stripe Axial Node Power Uncertainties}

The statistical sampling value for the axial node plate power in the stripe, $\left[p_{j}\right]_{j}$, for axial node $\mathrm{j}$ is obtained from

$$
\left[p_{j}\right]=\theta_{j}\left[u_{j}\right] P_{s}
$$

Where

$\theta_{\mathrm{j}}=$ input axial power shape, normalized to sum to 1.0

$\left[\mathrm{u}_{\mathrm{j}}\right]=$ local power uncertainty factor, obtained by statistical sampling from the local power distribution.

The code has options to obtain a separate value for uj for each axial node or to use the same value for all nodes in a plate.

\section{Axial Node Coolant Temperatures}

The axial node coolant temperature, $\mathrm{T}_{\mathrm{wj}}$, at the bottom of node $\mathrm{j}$ is obtained by starting with the inlet temperature for node 1 and then using

$$
\mathrm{T}_{\mathrm{wj}+1}=\mathrm{T}_{\mathrm{wj}}+\mathrm{p}_{\mathrm{wj}} /\left(\mathrm{W}_{\mathrm{s}} \mathrm{C}_{\mathrm{p}}\right)
$$

where the value of $\mathrm{p}_{\mathrm{wj}}$, the power in the coolant, depends on the options being used. For an interior channel for the single plate option and a full coolant channel, $\mathrm{p}_{\mathrm{wj}}$ is equal to $\left[\mathrm{p}_{\mathrm{j}}\right]$. For an interior channel with the two plate option, $p_{w j}$ is the average of the $\left[p_{j}\right]$ for the two plates. For an end channel facing an unheated surface, $p_{w j}$ is half of $\left[p_{j}\right]$.

A two-step iteration is used for each axial node to make the temperature-dependent value of $C_{p}$ consistent with the calculated coolant temperatures.

\section{Axial Node Coolant Pressures and Saturation Temperatures}

The coolant pressure at the top of the core is calculated, based on the height of the water above the core and the coolant outlet temperature. Then the pressure drop in each axial node is calculated, 
based on friction and gravity head. The saturation temperature at each node is obtained after the pressures are calculated.

\section{Axial Node ONB Temperatures}

The Bergles-Rohsenow correlation predicts the fuel clad temperature at which ONB occurs [Ref. 6].

$$
T_{\text {clad, ONB }}=T_{\text {sat }}+0.556\left[\frac{q^{\prime \prime}}{1082 \cdot p^{1.156}}\right]^{0.463 \cdot p^{0.0234}}
$$

Where

$\mathrm{T}_{\text {clad, } \mathrm{ONB}}=$ fuel clad temperature $\left({ }^{\circ} \mathrm{C}\right)$ at which ONB occurs,

$\mathrm{T}_{\text {sat }}=$ saturation temperature $\left({ }^{\circ} \mathrm{C}\right)$,

$\mathrm{q}^{\prime \prime}=$ local heat flux $(\mathrm{W} / \mathrm{m} 2)$, and

$\mathrm{p}=$ pressure $(\mathrm{bar})$.

\section{Carnavos Fin Heat Transfer Coefficients and Clad Surface Temperatures}

The fin heat transfer coefficients are calculated using the Carnavos correlation [Ref. 7]. The Carnavos correlation is an empirical correlation based on 11 finned tubes of different number of fins, fin height, fin helix angles and tube diameters. The fins were on the inside surface of the tubes. Carnavos fitted experimental data from these tests to obtain this correlation within $10 \%$ error. The correlation is applicable for $10000<\operatorname{Re}<100000$ and is given as:

$$
\mathrm{Nu}=0.023 \cdot \operatorname{Re}_{a}^{0.8} \cdot \operatorname{Pr}^{0.4} \cdot\left(\frac{A_{f a}}{A_{f c}}\right)^{0.1} \cdot\left(\frac{A_{n}}{A_{a}}\right)^{0.5} \cdot \sec ^{3} \alpha
$$

where $\mathrm{Nu}=\mathrm{h} D_{\text {ha }} / \mathrm{k}$

$\mathrm{Nu}$, Re and Pr are Nusselt, Reynolds and Prandtl Number, respectively. Other terms in the Carnavos correlation and their counterparts in MITR-II are summarized in Table 2.

It should be noted that the definition of the $A_{f c}$ term is somewhat ambiguous in the Carnavos paper: the term is mentioned in the paper but not defined in the Nomenclature section where the other terms are defined, so it is necessary to infer the meaning from other information in the paper. An initial guess for the meaning was used for the Oracle-Crystal Ball calculations described in Section 5.4 and for STAT6 and earlier versions of the STAT code. A careful examination of the paper showed that a different interpretation given in Table 2 is correct. This corrected interpretation corresponds exactly to the values given in the paper for the "open core free flow area" for experiments used to derive the Carnavos correlation. The corrected interpretation is used in STAT7. For typical MIT cases the difference in the heat transfer coefficient due to the error in $A_{f c}$ is only about $2 \%$.

The clad surface temperatures are calculated from the coolant temperatures, the heat transfer coefficients and the clad heat fluxes. Additional discussion on fins is provided in Appendix A. 
Table 2. Geometry parameters in Carnavos correlation and derived values for an inner channel of an LEU fuel element

\begin{tabular}{|c|c|c|}
\hline Symbol & Meaning & Counterpart in MITR element \\
\hline$A_{f a}$ & Actual free flow area & $\begin{array}{l}\text { Stripe Width } \times\left(\text { water gap }{ }^{*}+2\right. \\
\times \text { fin height })-2 \times \text { number of } \\
\text { fins per stripe } \times \text { single fin area }\end{array}$ \\
\hline$A_{f c}$ & $\begin{array}{l}\text { Open core free flow area, } \\
\text { fin tip-fin tip }\end{array}$ & Stripe width $\times$ water gap ${ }^{*}$ \\
\hline$A_{n}$ & $\begin{array}{l}\text { Nominal heat transfer area } \\
\text { based on tube inner diameter } \\
\text { as if fins were not present }\end{array}$ & $\begin{array}{l}\text { Nominal heated perimeter } \times \\
\text { fuel length }\end{array}$ \\
\hline$A_{a}$ & $\begin{array}{l}\text { Actual heat transfer area } \\
\text { Actual heat transfer area }\end{array}$ & $\begin{array}{l}\text { Actual heated perimeter } \times \text { fuel } \\
\text { length }\end{array}$ \\
\hline$\alpha$ & Helix angle in finned tube & 0 \\
\hline$D_{h a}$ & Actual hydraulic diameters & $\begin{array}{c}(4 \times \text { actual flow area) } /(\text { actual } \\
\text { wetted perimeter })\end{array}$ \\
\hline
\end{tabular}

* water gap refers to the fin-tip to fin-tip distance

\subsection{Carnavos Friction Factor for Fins}

In addition to the heat transfer coefficients for finned surfaces mentioned above, Carnavos also measured friction factors for finned tubes. The data was fit by:

$$
\mathrm{f}=0.184 /\left[\operatorname{Re}^{0.2}\left(\mathrm{~F}^{*}\right)\right]
$$

where

$\mathrm{f}=$ friction factor

$\mathrm{Re}=$ actual Reynolds number

$F^{*}=\left(A_{f a} / A_{f n}\right)^{0.5}(\operatorname{Sec}[\alpha])^{0.75}$

$\mathrm{A}_{\mathrm{fa}}=$ actual free flow area, $\mathrm{mm}^{2}$

$\mathrm{A}_{\mathrm{fn}}=$ nominal flow area based on tube ID as if the fin structure were not present, $\mathrm{mm}^{2}$

$\operatorname{Sec}[\alpha]=1.0$ for fins parallel to the flow

Use

$\mathrm{f}_{\text {fin }}=1 / \mathrm{F}^{*}=$ friction factor multiplier for fins

$\mathrm{g}$ = gap (fin-tip to fin-tip for an interior channel, fin-tip to end of channel for an end channel)

$\mathrm{d}_{\mathrm{g}}=$ groove depth $=$ fin height

$\mathrm{w}_{\mathrm{g}}=$ groove width

$\mathrm{w}_{\mathrm{f}}=$ fin width

$\mathrm{W}_{\text {stripe }}=$ width of stripe

$\mathrm{G}_{\mathrm{rf}}=$ average groove gap factor $=\mathrm{w}_{\mathrm{g}} /\left(\mathrm{w}_{\mathrm{g}}+\mathrm{w}_{\mathrm{f}}\right)$

Interior Channel, fins on both sides

$$
\begin{aligned}
& A_{f a}=W_{\text {stripe }}\left(g+2 d_{g} G_{r f}\right) \\
& A_{\text {fn }}=W_{\text {stripe }}\left(g+2 d_{g}\right) \\
& f_{\text {fin }}=\left[\left(g+2 d_{g}\right) /\left(g+2 d_{g} G_{r f}\right)\right]^{0.5}
\end{aligned}
$$


End Channel, fins on one side

$$
\begin{aligned}
& A_{f a}=W_{\text {stripe }}\left(g+d_{g} G_{r f}\right) \\
& A_{\text {fn }}=W_{\text {stripe }}\left(g+d_{g}\right) \\
& f_{\text {fin }}=\left[\left(g+d_{g}\right) /\left(g+d_{g} G_{r f}\right)\right]^{0.5}
\end{aligned}
$$

The hot stripe coolant flow rate, ws, calculated by Eqn. 4, is then multiplied by a fin flow multiplier, fwm, given by

$$
f_{w m}=\left(f_{\text {fin }} / f_{\text {fin } 0}\right)^{\text {ffrat }}
$$

where

$\mathrm{f}_{\text {fin } 0}=$ value for a nominal interior channel, and

ffrat $=-1 /(2+b f r)$

if $\mathrm{bfr}=-0.2$, then ffrat $=-0.5556$

\subsection{Statistical Sampling}

The statistical sampling method is taken from a mathematical handbook [Ref. 8]. A random variable $Y$ is said to be normally distributed with mean $m$ and standard deviation $\sigma$ if the probability, $I_{p}$, that $Y$ is less than or equal to $y$ is given by

$$
I_{p}(Y \leq y)=\frac{1}{\sigma \sqrt{2 \pi}} \int_{-\infty}^{y} e^{\frac{-(t-m)^{2}}{2 \sigma^{2}}} d t
$$

or if $x=(y-m) / \sigma$, then

$$
I_{p}(x)=\frac{1}{\sqrt{2 \pi}} \int_{-\infty}^{x} e^{-\left(t^{2} / 2\right)} d t
$$

Define $I_{q}(x)=1-I_{p}(x)$

Then if a random number, $r$, evenly distributed from 0 to 1 is obtained from a random number generator, then sampling from a normal distribution is obtained by obtaining the value of $\mathrm{x}$ for which

$$
\mathrm{r}=I_{p}(x)
$$

Alternatively, one can obtain random sampling from a normal distribution by using

$$
\mathrm{r}=I_{q}(x)
$$

Reference 4 gives a rational approximation for $x(\mathrm{r})$ where $\mathrm{r}=I_{q}(x)$

for $\mathrm{r} \leq 0.5$

$$
\mathrm{x}(\mathrm{r})=\mathrm{v}-\left(\mathrm{c}_{0}+\mathrm{c}_{1} \mathrm{v}+\mathrm{c}_{2} \mathrm{v}^{2}\right) /\left(1+\mathrm{d}_{1} \mathrm{v}+\mathrm{d}_{2} \mathrm{v}^{2}\right)+\varepsilon(\mathrm{r})
$$




$$
\begin{array}{ll}
v=\sqrt{\ln \frac{1}{\mathrm{r}^{2}}} & \\
\mathrm{c}_{0}=2.515517 & \mathrm{~d}_{1}=1.432788 \\
\mathrm{c}_{1}=0.802853 & \mathrm{~d}_{2}=0.189269 \\
\mathrm{c}_{2}=0.010328 & \mathrm{~d}_{3}=0.001308 \\
|\varepsilon(\mathrm{r})|<4.5 \times 10^{-4} & \\
\text { for } \mathrm{r}>0.5 & \\
x(\mathrm{r})=-x(1-\mathrm{r}) &
\end{array}
$$

\subsection{Comparison with Oracle-Crystal Ball Results}

A consistent series of cases for various coolant outlet temperatures was run with the Oracle Crystal Ball approach [Ref. 9] and with the STAT6 code. Figure 4 shows the results. For an outlet temperature of $60^{\circ} \mathrm{C}$, the results are almost identical, indicating that both approaches are equivalent.

Note that for this comparison the local power uncertainty used was $10 \%$ (3-sigma). The slight difference in slopes in Figure 4 is probably due to differences in the treatment of the temperature dependence of water properties where STAT calculates temperature-dependent water properties using the axial node temperatures for each history.

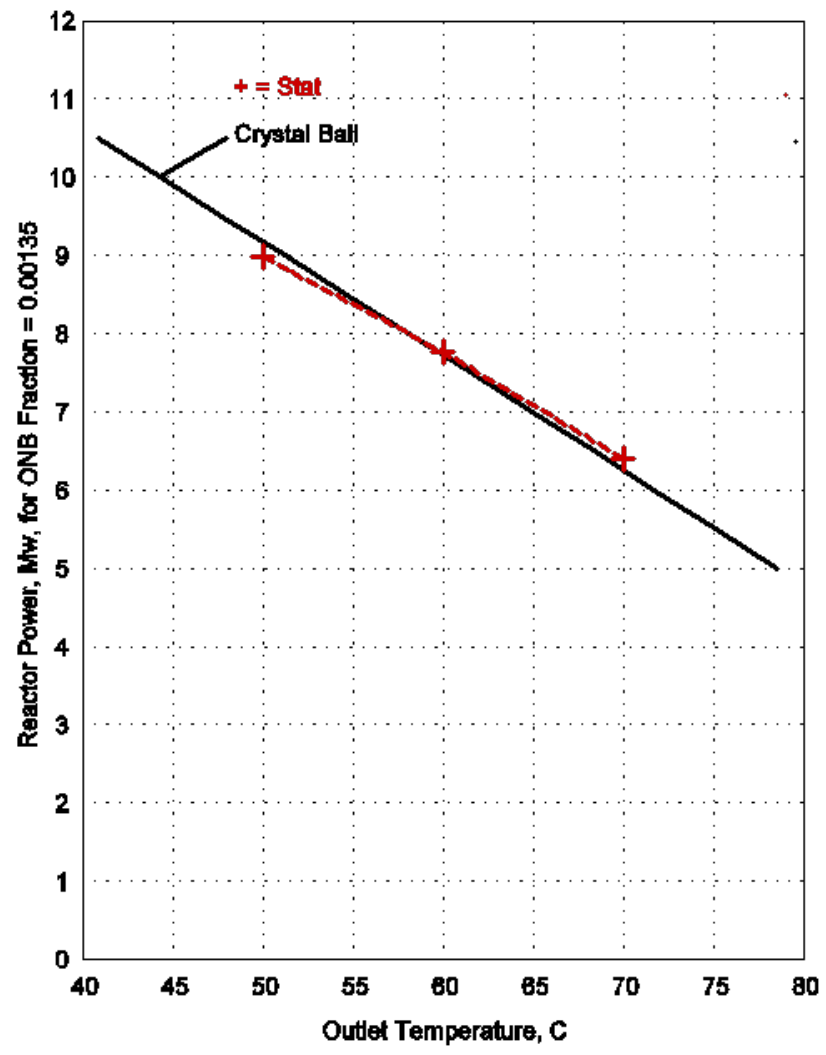

Figure 4. Comparison of STAT and Oracle-Crystal Ball Results 
There are three advantages to the STAT6 code over the Oracle-Crystal Ball approach. The first advantage is that setting up the STAT input and running the code is much simpler and less time consuming. Oracle-Crystal Ball requires hand iteration to obtain a consistent solution. All iteration in STAT is done internally by the code. Another advantage is that the STAT code can be easily expanded and integrated into a 3-D fuel management program. The third advantage is computing speed. The STAT calculations for one outlet temperature for 250,000 histories and ONB tests at all 18 axial nodes run in seconds. The Oracle-Crystal Ball computer time is substantially longer because it is a general purpose software with a spreadsheet interface. 


\section{THE STAT7 CODE}

The STAT7 code is an expansion of the STAT6 code to treat $N_{c h}$ coolant channels and $N_{p l}=N_{c h}+1$ plates. This code can model one stripe of all of the plates and coolant channels in an element, from end channel through the internal channels to the other end channel. When modeling an element containing $\mathrm{N}_{\mathrm{fp}}$ fuel plates there are $\mathrm{N}_{\mathrm{fp}}-1$ internal channels and 2 end channels. Also, an extra plate is added before the first end channel and another after the last end channel to account for whatever is beyond the end channels. If the end channel butts up against the end channel of an adjacent element, then the extra plate can model half of the end fuel plate of the adjacent element, with a zero heat flux boundary condition at the middle of the plate. If the end channel butts up against an unheated side plate of an adjacent element or against an unheated structural wall, then the only impact of the extra plate is to contribute to the wetted perimeter used in computing the hydraulic diameter of the end channel.

Even though the STAT7 was produced to model one stripe of all of the plates and coolant channels in an element, it can model other cases. If the end channel of one element butts up against the end channel of an adjacent element, then the code can model one stripe of both elements. Another option is to model only part of an element to determine the sensitivity of the results to how much of the element is modeled.

\subsection{Power Splits}

When calculating steady-state temperatures for a series of plates separated by coolant channels, zero heat flux boundary conditions at the centers of the plates cannot be assumed. Instead, a power split must be calculated for each axial node of each plate. The power split for a plate surface is defined as the ratio of the heat flux from the surface to the sum of the heat fluxes from both surfaces. The approach taken in STAT7 for calculating power splits involves assuming that the plate power density is uniform across the thickness of the fuel. Then a zero heat flux boundary condition occurs a fraction $f_{p s}$ of the way across the thickness of the fuel. The value of the flow split is set so that the peak fuel temperature calculated starting from the bulk coolant temperature on one side of the plate equals the peak fuel temperature calculated starting from the other side. For the extra plates at the ends, the power split is assumed to be 0.5 at all axial nodes.

\subsection{STAT7 Thermal Hydraulic Solution for a History}

\section{Nomenclature:}

$\mathrm{i}=$ coolant channel number

$\mathrm{Ni}=$ number of coolant channels in the model = nchan (input value)

$\mathrm{Ne}=$ number of elements in the core $=$ nelm (input)

$\mathrm{Np}=$ number of plates in the model $=\mathrm{Ni}+1$

$\mathrm{Npe}=$ number of plates per element

Ns $=$ number of stripes $/$ plate

$\mathrm{Nz}=$ number of axial nodes $=\mathrm{nz}$ (input)

$\mathrm{j}=$ axial node

$\mathrm{k}=$ plate number. Plate $\mathrm{k}$ is in contact with coolant channels $\mathrm{k}-1$ and $\mathrm{k}$

$\mathrm{l}=$ plate surface number. Surface 1 is in contact with channel $\mathrm{k}-1$. Surface 2 is in contact with channel $\mathrm{k}$

Ac(i) = coolant flow area

The STAT7 Code for Statistical Propagation of Uncertainties In Steady-State Thermal Hydraulics Analysis of Plate-Fueled Reactors 
$\operatorname{Dh}(\mathrm{i})=$ hydraulic diameter

$\mathrm{df}=$ flow disparity factor $=\mathrm{df}$ (input), accounts for element to element flow variation

$\mathrm{ff}=$ coolant core flow fraction $=$ flwfac(input), this accounts for bypass flow

fin = ratio of the average interior channel flow to the average channel flow = (input), this accounts for the average end channel flow being different from half of the average interior channel flow.

fsf $=$ fraction of the coolant channel flow in the stripe region $=$ flstrf (input), this accounts for neglecting the flow between the side plate and the edge of the fuel foil.

$\mathrm{fc}=$ the fraction of the fission power deposited in the core region $=$ fcore (input)

fs $(\mathrm{k})=$ current plate stripe power/core average power $=\mathrm{fstrp}(\mathrm{k})$ (input)

Gap(i) = gap size

$\operatorname{Pp}(\mathrm{k}, \mathrm{j})=$ plate power for the sample

$\operatorname{Tw}(\mathrm{i}, \mathrm{j})=$ coolant temperature at bottom of node $\mathrm{j}$

$\operatorname{Tps}(\mathrm{k}, \mathrm{l}, \mathrm{j})=$ plate surface temperature

$\operatorname{Tfc}(k, l, j)=$ fuel-clad interface temperature

$\operatorname{Tf}(\mathrm{k}, \mathrm{l}, \mathrm{j})=$ peak fuel temperature, calculated from face $\mathrm{l}$

$\mathrm{Tx}=$ average coolant outlet temperature $=$ tout (input)

Tin $=$ coolant inlet temperature

Pro $=$ nominal reactor power $=$

$\operatorname{Pr}=$ reactor power for the history

Pso(k) = nominal plate power

Wpo = nominal pump mass flow

$\mathrm{Wp}=$ pump flow for the history

Tin = coolant inlet temperature

Ws(i) = stripe flow for the history

Woi = average nominal interior channel stripe flow times df (flow disparity factor)

\section{Statistical Sampling}

The statistical sampling value, $[Y]$, for a variable y with a fractional standard deviation of $\sigma$ is obtained by multiplying the mean value, Yo, by a statistical multiplier, Fy, given by

$$
\mathrm{Fy}=1+\mathrm{x} \sigma
$$

The method used to obtain $\mathrm{x}$ is described in Section 5.3.

\section{Reactor Power, Pump Flow, and Inlet Temperature}

The average coolant outlet temperature, Tx, the nominal (measured) reactor power and the nominal pump flow are supplied by the user in the input. The reactor power for the history, Pr, and the pump mass flow for the history, $\mathrm{Wp}$, are obtained by statistical sampling. Then the inlet coolant temperature, Tin, is obtained from

$$
\operatorname{Tin}=\mathrm{Tx}-\operatorname{Pr} \mathrm{fc} /(\mathrm{WpCp})
$$

Where the coolant heat capacity $\mathrm{Cp}$ is evaluated at a temperature Tav given by

$$
\operatorname{Tav}=(\operatorname{Tin}+\mathrm{Tx})
$$

A two-step iteration between equations 16 and 17 is used to obtain consistency between Tav and $\mathrm{Cp}$.

The STAT7 Code for Statistical Propagation of Uncertainties In Steady-State Thermal Hydraulics Analysis of Plate-Fueled Reactors 


\section{Gap Size, Coolant Flow Area, Hydraulic Diameter}

The gap size, Gap(i), is obtained for each coolant channel by statistical sampling. Then the coolant flow area, Ac(i), and hydraulic diameter, Dh(i) are calculated. Note that the unfueled sides of the plate are neglected in the calculations for flow area, hydraulic diameter and coolant flow rate.

\section{Coolant Channel Mass Flow Rates}

The channel flow rate splits are calculated based on obtaining the same friction pressure drop in all channels. At normal pump flow rates gravity heads are insignificant compared to friction head losses. Orifice pressure losses are also small compared to friction. The friction pressure drop, $\Delta \mathrm{p}(\mathrm{i})$, for a channel is:

$$
\Delta \mathrm{p}(\mathrm{i})=[\mathrm{fr} \mathrm{L} / \mathrm{Dh}(\mathrm{i})][\mathrm{Ws}(\mathrm{i}) / \operatorname{Ac}(\mathrm{i})]^{2} /(2 \rho)
$$

where $\rho$ is the density, $\mathrm{L}$ is the channel length, and fr is the friction factor given by

$$
\mathrm{fr}=\mathrm{af} \mathrm{Re}^{\mathrm{bf}}
$$

where

Re $=$ Reynolds number $=\operatorname{Dh}(\mathrm{i}) \mathrm{Ws}(\mathrm{i}) /[\mu \mathrm{Ac}(\mathrm{i})]$

af, bf are correlation coefficients

$\mu=$ average viscosity

Usually af $=0.316$ and $b f=-0.25$ if Re is less than 20,000. For higher Re, af $=0.184$ and $b f=-0.2$. Combining equations $18-20$ gives:

$$
\text { Ws(i) }=\mathrm{CAc}(\mathrm{i}) \operatorname{Dh}(\mathrm{i})^{\mathrm{c} 2} \mu(\mathrm{i})^{\mathrm{c} 3}
$$

where

$\mathrm{C}$ is a constant

and

$$
c 2=(1-b f) /(2+b f)=0.714 \text { if } b f=-0.25 \text { or } .667 \text { if } b f=-0.2
$$

$$
c 3=b f /(2+b f)=-0.143 \text { if } b f=-0.25 \text { or }-0.111 \text { if } b f=-0.2
$$

The reference flow is calculated as

$$
\text { Woi = Wpo ff df fin fsf / (Ne Np Ns) }
$$

where

$$
\text { Woi = average nominal interior channel stripe flow times df (flow disparity factor) }
$$

The reference flow is calculated once and used for all histories. Also, Aco and Dho, the nominal interior channel flow area and hydraulic diameter, are calculated for the nominal interior gap size; and $\mu_{0}$, the nominal average viscosity is calculated for the nominal average coolant temperature. Then for a given history the channel flow rates are calculated as

$$
\text { Ws(i) }=\text { Woi }[\text { Ac(i) / Aco }][\operatorname{Dh}(\mathrm{i}) / \text { Dho }]^{c 2}
$$


If the bypass option is used, flow fraction ff needs to be calculated as

$$
\mathrm{ff}=\text { wtotel } /(\text { wtotel }+ \text { wbyp })
$$

where wtotel is total core flow calculated by

$$
\text { wtotel }=\operatorname{Sum}(\mathrm{Ws}(\mathrm{i})) * \mathrm{Ne} * \mathrm{Ns} /(\mathrm{df} * \mathrm{fsf})
$$

and wbyp is bypass flow rate calculated by

$$
\text { wbyp = Woi [acbyp / Aco ] [dhbyp / Dho]c2 }
$$

An iteration is performed with the equations from 24 to $24 \mathrm{~d}$ to obtain channel and bypass flowrates.

If the viscosity effect on flow is taken into account, the equation (24a) for channel flowrates becomes

$$
\text { Ws(i) }=\text { Woi }[\operatorname{Ac}(\mathrm{i}) / \operatorname{Aco}][\mathrm{Dh}(\mathrm{i}) / \mathrm{Dho}]^{\mathrm{c} 2}\left[\mu(\mathrm{i}) / \mu_{\mathrm{o}}\right]^{\mathrm{c} 3}
$$

The viscosity effect in equation 25 is only calculated approximately. The coolant channel flow rates are calculated before the fuel plate power splits, so power splits of 0.5 everywhere are used for the calculation of the average coolant temperature to use for $\mu(\mathrm{i})$. The accuracy of the viscosity effect could be improved by iterating between the power split calculation and the flow calculation, but the viscosity effect is fairly small, and a moderate improvement in the effect would make little difference in the plate surface temperatures. Also, the equation (24d) for bypass flowrate becomes

$$
\text { wbyp = Woi [acbyp / Aco ] [dhbyp / Dho }]^{\mathrm{c} 2}\left[\mu \text { byp / } \mu_{\mathrm{o}}\right]^{\mathrm{c} 3}
$$

\section{Carnavos Fin Factor}

The Carnavos fin heat transfer factor is calculated using Equation 8.

\section{Power Plate Profiles}

The plate power for 1 stripe for each node of each plate, $\operatorname{Pp}(k, j)$, is obtained by statistical sampling.

\section{Coolant Heat Transfer Coefficient Statistical Multiplier}

A coolant heat transfer multiplier is obtained by statistical sampling. For each sample only one heat transfer multiplier is used for all nodes of all plate surfaces. This may be excessively conservative, but it is likely that the heat transfer coefficient uncertainties are systematic, and applying to all nodes of all surfaces, rather than random, and differing from node to node and from surface to surface.

\section{Power Splits}

The power split calculation requires solving for the splits for all plates at a given axial node simultaneously, starting from the inlet node and working up one node at a time. The power split, Fps1(k,j) for node $\mathrm{j}$ of plate $\mathrm{k}$ is defined as the ratio of the flux at surface 1 to the sum of the fluxes at both surfaces. Surface 1 is in contact with coolant channel k-1, and surface 2 is in contact with coolant channel k. The power splits are calculated so that the peak fuel temperature, $\operatorname{Tf}(\mathrm{k}, \mathrm{l}, \mathrm{j})$, calculated from surface 1 equals that calculated from surface 2 . 
At the beginning of the calculations for node $\mathrm{j}$, the coolant temperatures, Tw(i,j), at the bottom of the node for all channels are known. Then,

$$
\operatorname{Tw}(i, j+1)=\operatorname{Tw}(i, j)+\{[1-\operatorname{Fps} 1(i, j)] P p(i, j)+\operatorname{Fps} 1(i+1, j) P p(i+1, j)\} /[W s(i) C p]
$$

Then the average coolant temperature for the axial node is:

$$
\operatorname{Twa}(\mathrm{i}, \mathrm{j})=[\operatorname{Tw}(\mathrm{i}, \mathrm{j})+\operatorname{Tw}(\mathrm{i}, \mathrm{j}+1)] / 2
$$

The plate surface temperatures, Tps(k,l,j), are obtained from:

$$
\begin{aligned}
& \operatorname{Tps}(k, 1, j)=\operatorname{Twa}(k-1, j)+\operatorname{Flxs}(k, 1, j) / \operatorname{Hw}(k, 1, j) \\
& \operatorname{Tps}(k, 2, j)=\operatorname{Twa}(k, j)+\operatorname{Flxs}(k, 2, j) / \operatorname{Hw}(k, 2, j)
\end{aligned}
$$

where

$\mathrm{Hw}(\mathrm{k}, \mathrm{l}, \mathrm{j})=$ coolant heat transfer coefficient, including the Carnavos fin factor and the coolant heat transfer statistical multiplier.

and the plate surface heat flux, Flxs(k,l,j) is:

$$
\begin{aligned}
& \operatorname{Flxs}(k, 1, j)=\operatorname{Fps} 1(k, j) P p(k, j) \operatorname{Fpf} / \operatorname{Sf}(k) \\
& \operatorname{Flxs}(k, 2, j)=[1-\operatorname{Fps} 1(k, j)] \operatorname{Pp}(k, j) F p f / S f(k)
\end{aligned}
$$

where

$\mathrm{Sf}(\mathrm{k})=$ plate surface area of 1 stripe of 1 node, including fins, and

Fpf $=$ fraction of the power deposited in the fuel $=$ ffuel (input)

Note that the power deposited in the clad is not accounted for separately; it should be included in Fpf. The fuel - clad interface temperature, $\operatorname{Tfc}(\mathrm{k}, \mathrm{l}, \mathrm{j})$, is calculated as

$$
\begin{aligned}
& \operatorname{Tfc}(k, 1, j)=\operatorname{Tps}(k, 1, j)+\operatorname{Flxo}(k, 1, j) C t / K c \\
& \operatorname{Tfc}(k, 2, j)=\operatorname{Tps}(k, 2, j)+\operatorname{Flxo}(k, 2, j) C t / K c
\end{aligned}
$$

where

Ct and Kc are clad thickness and conductivity, respectively.

$$
\begin{aligned}
& \text { Flxo(k,1,j) = Fps1(k,j) Pp(k,j) Fpf } / \text { So(k) } \\
& \operatorname{Flxo}(k, 2, j)=[1-\operatorname{Fps} 1(k, j)] \operatorname{Pp}(k, j) F p f / \operatorname{So}(k)
\end{aligned}
$$

$\operatorname{So}(\mathrm{k})=$ plate surface area of 1 stripe of 1 node, not including fins 
Based on the analytic temperature solution for a uniformly heated slab with a zero heat flux boundary on one side, the peak fuel temperature calculated from surface $l, \operatorname{Tf}(k, l, j)$, is

$$
\begin{aligned}
& \operatorname{Tf}(k, 1, j)=\operatorname{Tfc}(k, 1, j)+F s p 1(k, j)^{2} P p(k, j) F p f F t /[2 \text { So(k)Kf }] \\
& \operatorname{Tf}(k, 2, j)=T f c(k, 2, j)+[1-F s p 1(k, j)]^{2} P p(k, j) F p f F t /[2 \text { So(k)Kf] }
\end{aligned}
$$

Where

$$
\mathrm{Ft}=\text { fuel thickness. }
$$

Then, setting

$$
\operatorname{Tf}(k, 1, j)=\operatorname{Tf}(k, 2, j)
$$

gives

$$
\begin{aligned}
& \operatorname{Tw}(k-1, j)+\{[1-F p s 1(k-1, j)] P p(k-1, j)+F p s 1(k, j) P p(i k, j)\} /[2 W s(k-1) C p]+ \\
& \text { Fps1(k,j) Pp(k,j) Fpf / [Sf(k) Hw(k,1,j) ] + Fps1(k,j) Pp(k,j) Fpf Ct /[ So(k) Kc ] + } \\
& \text { Fsp1(k,j) })^{2} \text { Pp(k,j) Fpf Ft / [ } 2 \text { So(k) Kf] = } \\
& \operatorname{Tw}(k, j)+\{[1-F p s 1(k, j)] P p(k, j)+F p s 1(k+1, j) P p(i k+1, j)\} /[2 W s(k) C p]+ \\
& \text { [1 - Fps1(k,j)] Pp(k,j) Fpf / [Sf(k) Hw(k,2,j) ] + (1- Fps1(k,j)) Pp(k,j) Fpf Ct /[ So(k) Kc ] + } \\
& \text { [ } 1 \text { - Fps1(k,j) ] }]^{2} \text { Pp(k,j) Fpf Ft / [ } 2 \text { So(k) Kf] }
\end{aligned}
$$

Equation 34 involves Fsp1(k-1,j), Fsp1(k,j), and Fsp1(k+1,j). When combined with Fsp1(1,j)= Fsp1(Np,j) $=0.5$ it leads to a series of $\mathrm{N}$ equations in $\mathrm{N}$ unknowns. Because the equations include $\operatorname{Fsp}(k, j)^{2}$ and $[1-F s p 1(k, j)]^{2}$ the equations are not completely linear, and iteration is used to solve them. First, the squares are linearized using:

$$
\operatorname{Fps} 1(k, j)=F p s 1 o(k, j)+[F s 1(k, j)-F p s 1 o(k, j)
$$

where Fps1o is an initial guess for Fs1 or the computed value from the last iteration. Then:

$$
\operatorname{Fps} 1(k, j)^{2} \sim \operatorname{Fps} 10(k, j)^{2}+2[\operatorname{Fps} 1(k, j)-\operatorname{Fps} 10(k, j)] \operatorname{Fps} 10(k, j)=
$$

2 Fps1(k,j) Fps1o(k,j) - Fps1o(k,j)2

Similarly:

$$
\begin{aligned}
& (1-\text { Fps1 })=(1-\text { Fps1o })+[(1-\text { Fps1 })-(1-\text { Fps1o })]=(1-\text { Fps1o })+(\text { Fps1o }- \text { Fps1 }) \\
& (1-\text { Fps } 1)^{2} \sim(1-\text { Fps1o })^{2}+2\left[( 1 - \text { Fps1o } ) \left(\text { Fps1o }- \text { Fps1)] }=1-F_{p s} 1 o^{2}-2 \text { Fps1 }(1-\text { Fps1o })\right.\right.
\end{aligned}
$$

The linearized version of Equation 34 has the form:

$$
a a(k, j) \operatorname{Fpsl}(k-1, j)+b b(k, j) F p s 1(k, j)+c c(k, j) F p s 1(k+1, j)=d d(k, j)
$$


Equation 36 is solved by Gaussian elimination.

The power split iteration for an axial node for all of the plates in an element converges very rapidly. Two iterations are enough to produce an accurate result.

\subsection{Comparison of STAT7 Results with RELAP5 Results}

For verification of the STAT7 thermal hydraulic calculations, a comparison was made of the results from a STAT7 case and from a RELAP5 case that was set up to be equivalent to the STAT7 case. One stripe of an 18 fuel plate element with fins was modeled in both codes. The fins are 8 mils high, 10 mils wide and 10 mils apart, giving a surface area of 1.8 times as high as a no-fins case. STAT7 uses a Carnavos film heat transfer fin factor of 0.75 for this case. RELAP5 does not have a fin treatment, but fin heat transfer effects were accounted for by multiplying the plate surface area by $1.8 \times 0.75=1.35$. In order to obtain the correct temperatures in the plates, the clad and fuel thermal conductivities used in RELAP5 were divided by 1.35 .

STAT7 calculates steady-state coolant flow rates and temperatures. RELAP5 does not have a steadystate solver, so the RELAP5 case was run as a null transient with powers, total element flow, and the coolant inlet temperature held constant at the STAT7 values for 300 seconds. The RELAP5 transient results settled down to steady-state values well before 300 seconds.

Figure 5 shows the coolant mass flow rates by channel. For this case the end channels both had the same gap size, and all interior channels had a second same gap size. The small differences between the STAT7 results and the RELAP5 results are probably mainly due to the change in water viscosity with temperature: an effect that is not included in the STAT7 coolant channel flow rate calculation.

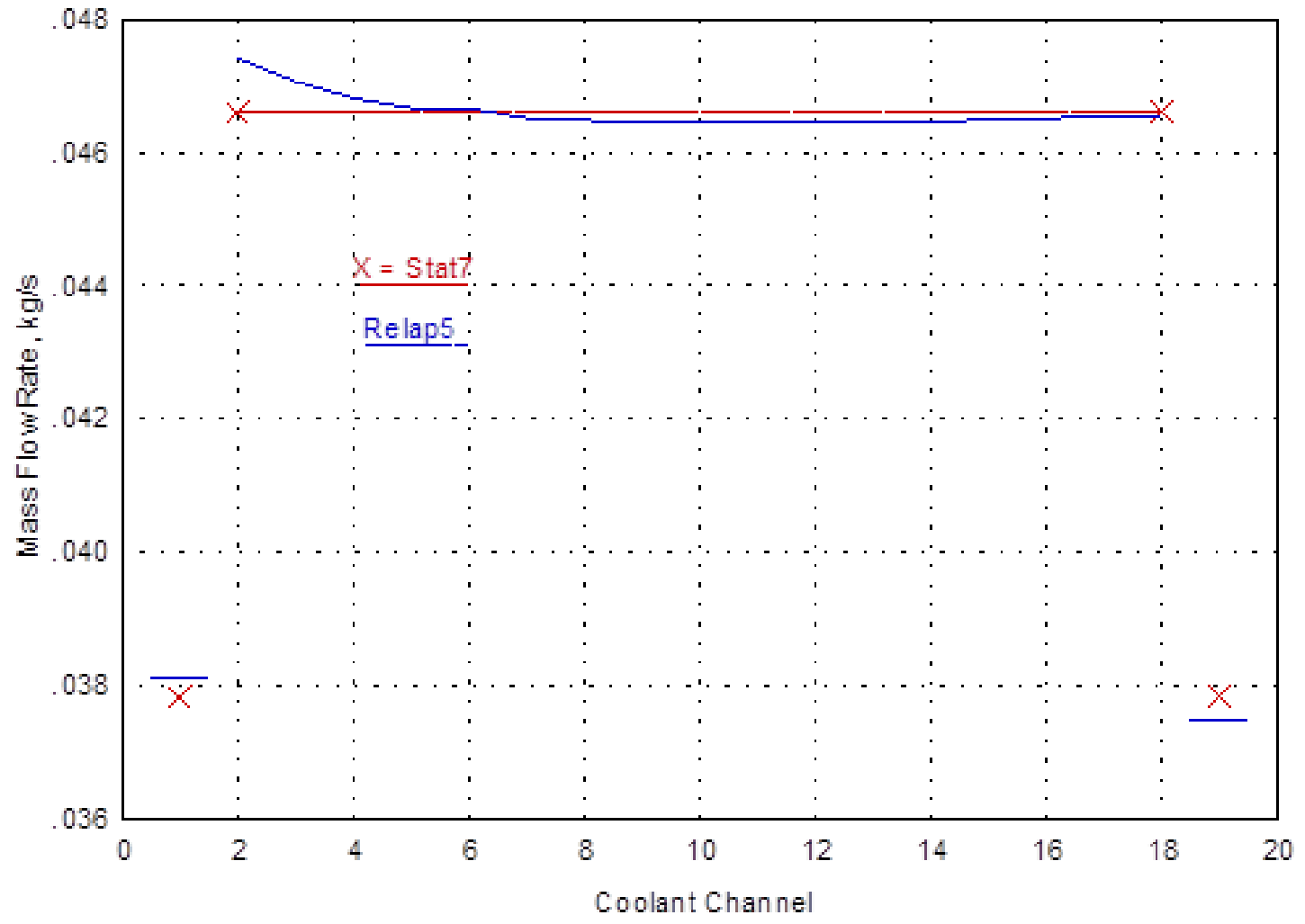

The STAT7 Code for Statistical Propagation of Uncertainties In Steady-State Thermal Hydraulics Analysis of Plate-Fueled Reactors 


\section{Figure 5. Comparison of STAT7 and RELAP5 End Channel and Interior Channel Flow Rates}

Figure 6 shows the coolant temperatures for the end channel and for the first two interior channels. One slight complication is that RELAP5 prints axial node coolant temperatures at the outlet (upper boundary) of the node and uses these node boundary coolant temperatures in the calculations for the axial node plate temperatures. STAT7 uses coolant temperatures at the middle of the axial node in the calculations for the axial node plate temperatures. The STAT7 temperatures in Figure 6 are mid-node temperatures and are plotted at the middles of the nodes. The RELAP5 temperatures in this figure are node boundary values plotted at the node boundaries. Thus the coolant temperatures in Figure 6 are plotted consistently. On the other hand, the axial node plate temperatures calculated by RELAP 5 are based on node boundary coolant temperatures but node average heat fluxes. In the following figures for plate temperatures, the axial node plate temperatures for both STAT7 and RELAP5 are plotted at the middle of the node. For RELAP5, the bulk coolant temperature rise in a full axial node, based on the node-average heat flux, is larger than the STAT7 bulk coolant temperature rise in half of an axial node.

Figure 7 and Figure 8 show the comparisons for the clad surface temperatures and the peak fuel temperatures. Figure 9 shows the comparisons for the plate power splits at each axial node.

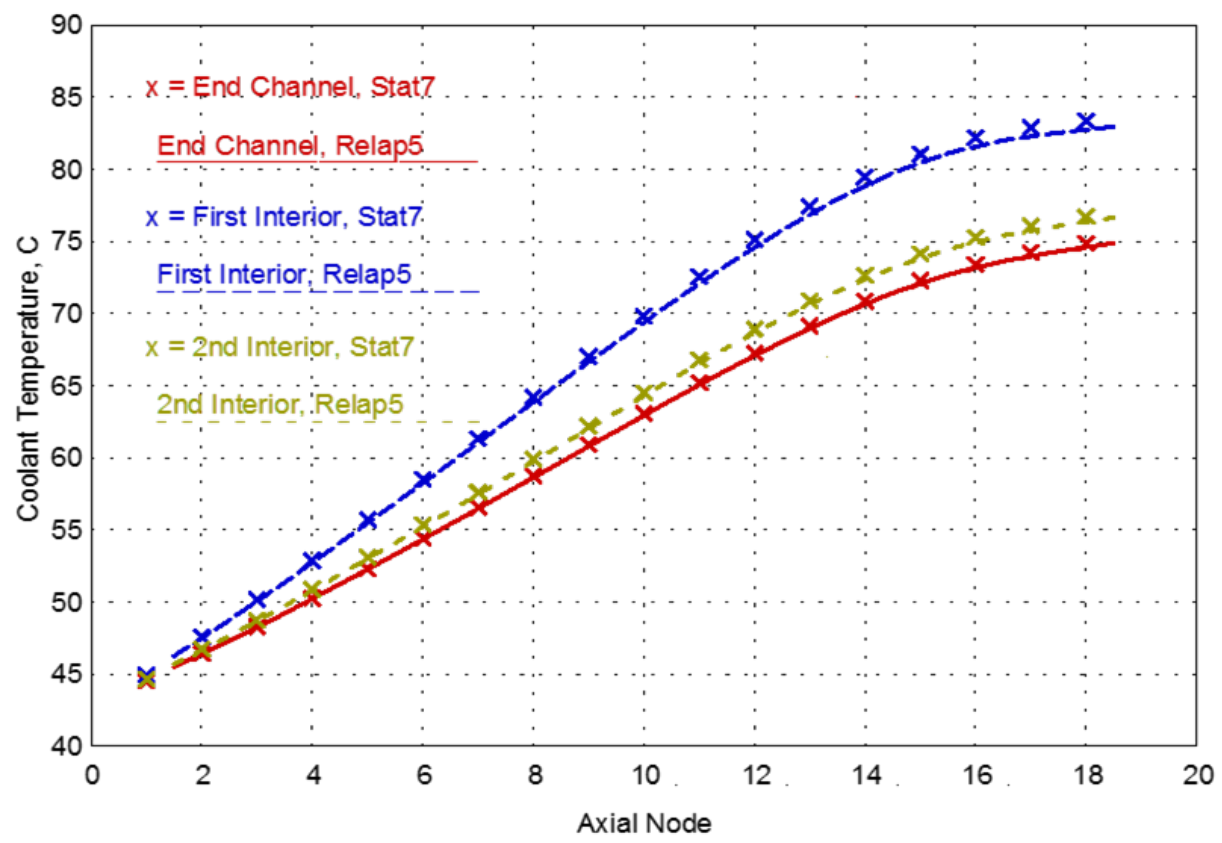

Figure 6. Comparison Between STAT7 and RELAP5 Coolant Temperatures for an End Channel and the First Two Interior Channels 


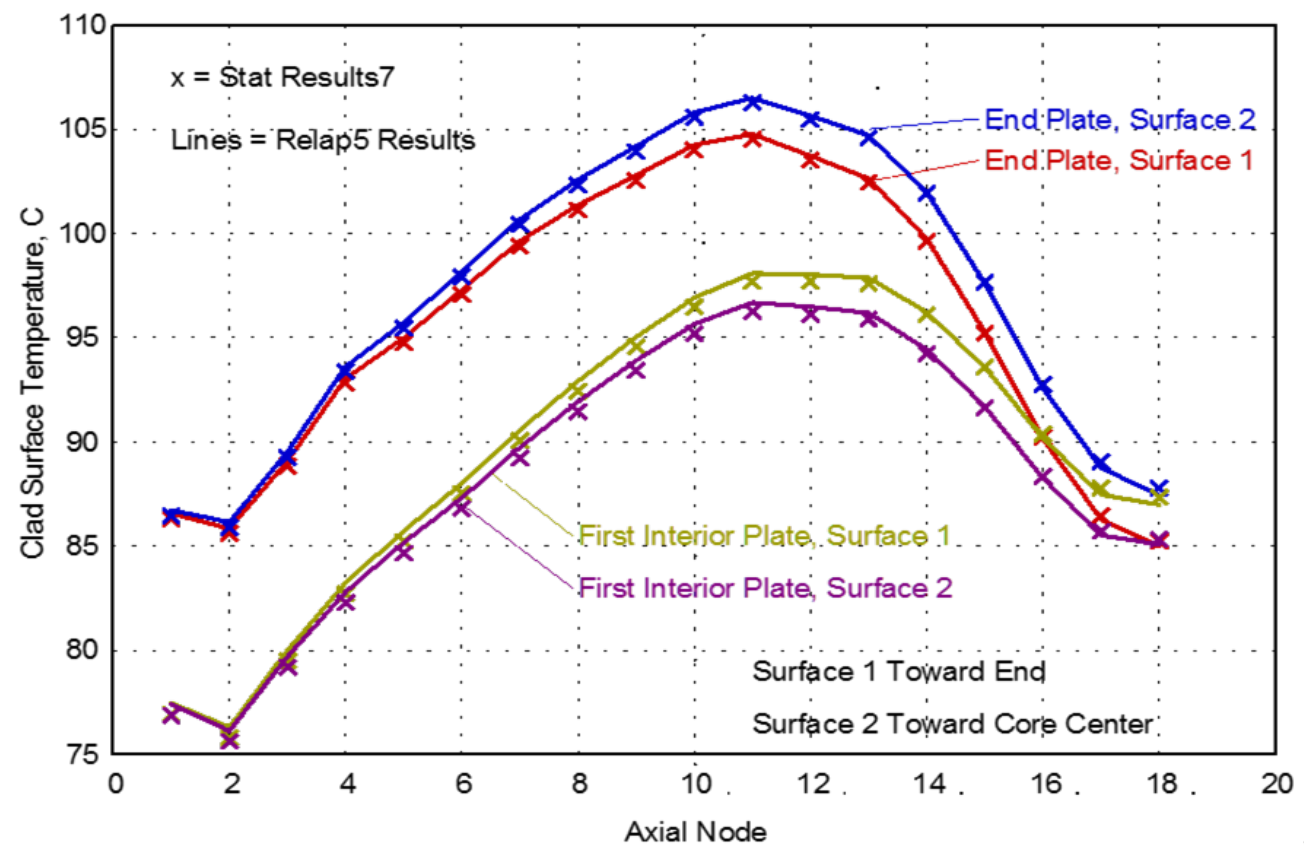

Figure 7. Comparison Between STAT7 and RELAP5 Clad Surface Temperatures for an End Plate and the First Interior Plate

The comparisons between STAT7 results and RELAP5 results for this family of channels verified, that the thermal hydraulic calculations in STAT7 have been implemented correctly. Also, the method used to account for fins in RELAP5 is consistent with the Carnavos treatment in STAT7. Also, the comparisons in Section 5.4 between STAT6 and Oracle-Crystal Ball results show that the statistical methods are equivalent. 


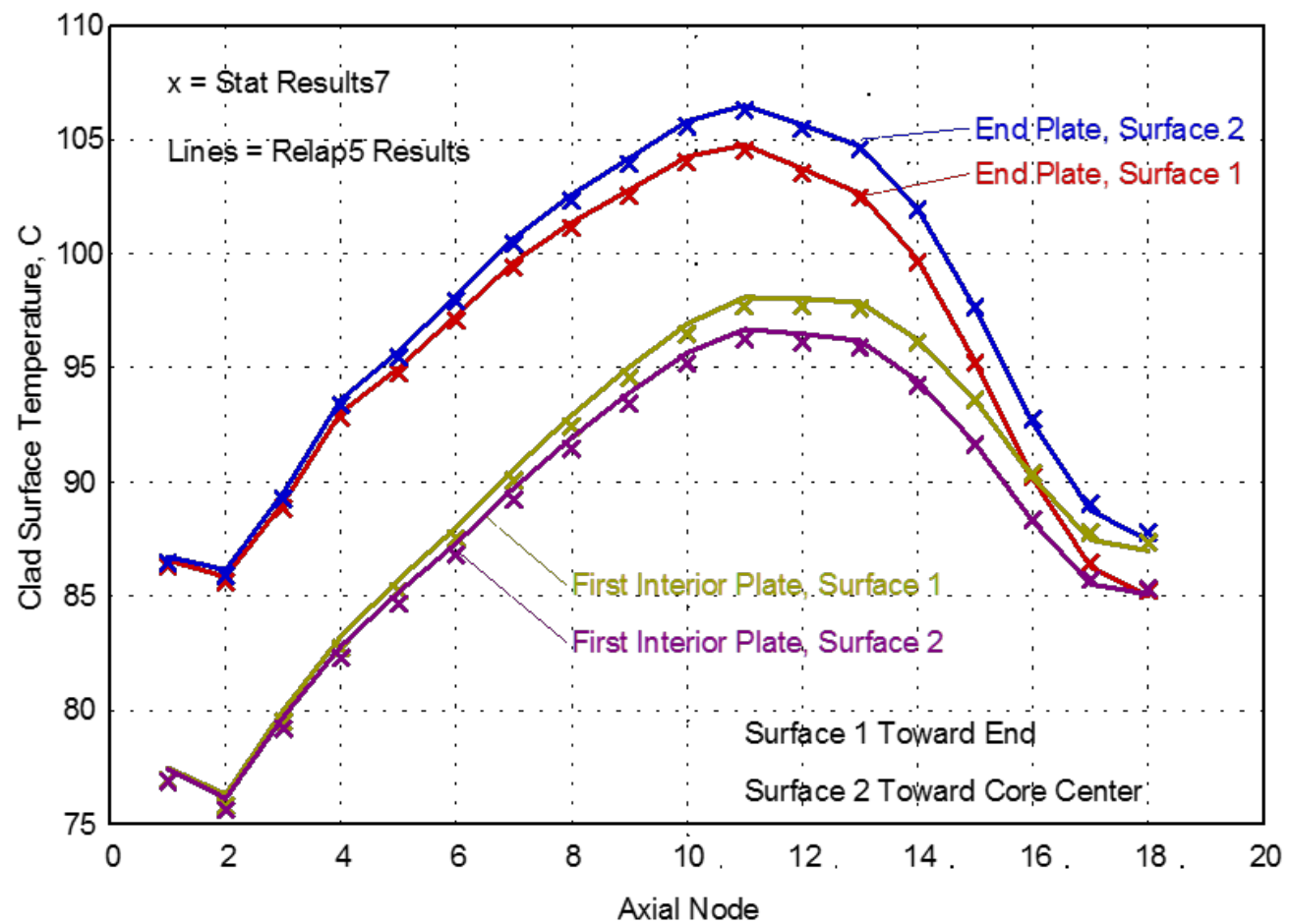

Figure 8. Comparison Between STAT7 and RELAP5 Peak Fuel Temperatures for an End Plate and the first Interior Plate

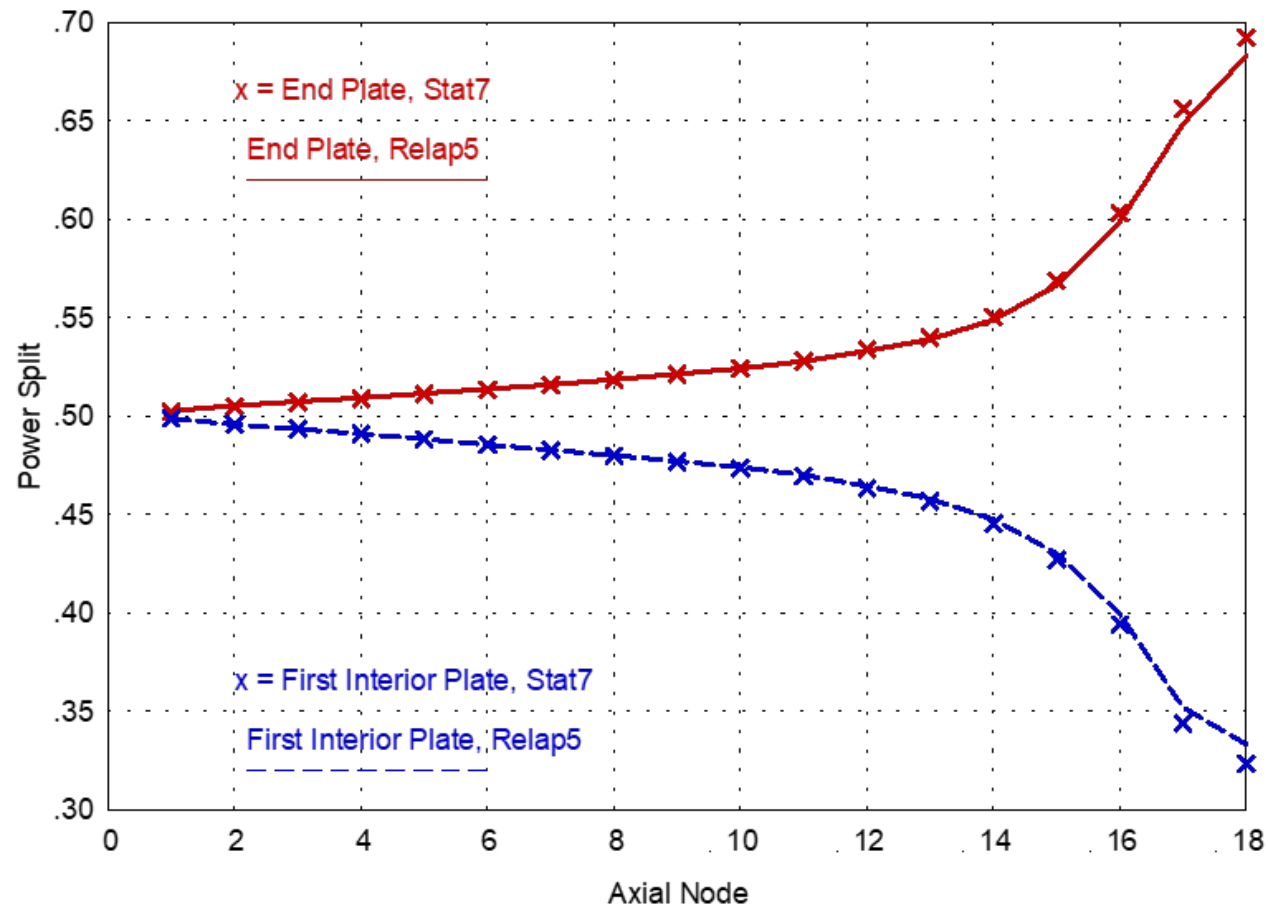

Figure 9. Comparison Between STAT7 and RELAP5 for Power Splits in an End Plate and the First Interior Plate 


\section{APPLICATION IN DETERMINATION OF MITR LSSS}

In summary, the LSSS are based on ONB in the core. Uncertainties are accounted for in the analysis by using Monte Carlo uncertainty propagation of the parameters influencing ONB, as discussed above. The requirement is that the measured total reactor power should have at least $20 \%$ margin to the power at which the ONB ( $\left.\mathrm{P}_{\mathrm{ONB}}\right)$ is found to occur with a 3-sigma confidence level of $99.865 \%$. The margin between HEU licensed power and LSSS power is $20 \%$, and so this should be maintained in the LEU case in order to provide an equivalent margin.

Using a 3-sigma confidence level of 99.865\%, the probability of ONB occurring in the most limiting element is $0.135 \%$ at $\mathrm{P}_{\mathrm{ONB}}$. As is the case in the HEU core, it is proposed that the total core reactor power, $\mathrm{P}_{\mathrm{r}}$, should have an additional $20 \%$ margin to the ONB power, $\mathrm{P}_{\mathrm{ONB}}$, such that $\mathrm{P}_{\mathrm{r}}=\mathrm{P}_{\mathrm{ONB}} / 1.2$. All channels of an element are analyzed, and each element is analyzed in this manner so that a whole core analysis may identify the most limiting locations for each core configuration considered. 


\section{INPUT DESCRIPTION}

\subsection{Input Formats}

STAT7 input is read by fixed format FORTRAN read statements, so spacing matters. Integers must be right-justified within the allotted spaces: otherwise zeroes will be added to the right to fill out the allotted spaces. Floating point numbers need to be within the allotted spaces. It is best to type the decimal point in a floating point number: otherwise the decimal point will be inserted at the location indicated by the format.

As an aid to the user, title lines are included in the input. As indicated in the sample input in Section 10 , the title lines can be used to list the variables being read and to indicate the spacing for the input. Each title line has a $20 \mathrm{a} 4$ format: 20 words, each 4 characters long, for a total of 80 spaces. The "a" format indicates character data. If less than 80 characters are entered, the rest will be filled with blanks. In STAT7 the title lines are read and then printed out as read. The code does not make any use of the information on a title line other than to print it out.

Most of the integer input uses 10i8 format. This indicates 10 integers, each 8 spaces long. Leading blanks are ignored. Trailing blanks are filled with zeroes. If there is no value supplied (blank or the line end precedes this input) the value is interpreted as zero.

Most of the floating point input uses $8 \mathrm{f} 10.5$ format. This indicates 8 numbers using 10 spaces per number. If no decimal point is typed, the decimal point will be added so that there are 5 numbers to the right of the decimal point. If the decimal point is typed, then it will be used where typed. Again leading blanks are ignored and trailing blanks are filled with zeroes. If there is no value supplied (blank or the line end precedes this input) the value is interpreted as zero.

\subsection{Input Description and Sample Values}

\section{Block 1: Case Title}

title (20a4)

Note: title $=80$ columns of title or comment information used for the case, or in subsequent lines as a comment text for names and alignment of input variables.

\section{Block 2: Integer Variable Input Lines}

title (20a4)

nelm, nplt, nstrp, nz, nbatch, nsmpl, isd1, isd2, iprt, idbstt (10i8)

nelm $=$ number of elements $=24$

nplt $=$ number of plates/element $=18$ (LEU)

Note: nplt is the number of real fuel plates/element. An element contains nplt - 1 interior coolant channels plus 2 end channels.

For a description of the differences between a real element and the computational model see "nchan" below.

nsrtp $=$ number of strips $/$ plate $=4$

$\mathrm{nz}=$ number of axial nodes in the stripe, $\max =40$

nbatch $=$ number of statistical sampling batches for a given nominal

power and nominal pump flow combination $=25$, $\max =100$

nsmpl = number of sampling calculations in each batch $=10000$

isd 1 and isd 2 are values used to calculate random number seed as $2 * * i s d 1+$ isd 2 
Default: isd $1=21$, isd $2=3$

iprt print detailed results for the first iprt samples

idbstt print statistical treatment debug prints if idbstt $>0$

title (20a4)

nchan, iaxpow, irndmn, ipow, iterpw, iend1, iendn, ivsc, niter, ilocp (10i8)

nchan = number of coolant channels in the case

Note: For the computational model an extra plate is added to each end to account for what is just beyond the element. Variables "iend1" and "iendn" determine the nature of the extra plates. . If nchan $=$ nplt +1 , then the case models one stripe of the whole element. Smaller values of nchan can be used to model one stripe of part of an element. If an end channel butts up to an end channel of an adjacent element, larger values of nchan can be used to model one stripe of one whole element plus part or all of the adjacent element.

iaxpow $=0$, all axial nodes use the same plocsg sample for local power statistical uncertainties

$=1$, each axial node uses a separate sample for local power statistical uncertainties

irndmn $>0$, use extra random number calls so that all iplat2 and iaxpow options use the same random numbers

ipow $=0$, local power uncertainties are independent of overall power uncertainties 1, the total power uncertainty factor, using powsgm, multiplies the local value, using plocsg

iterpw 0 , no power iteration

$>0$, iterate on power until ONB fraction $=$ epsonb

pow0 is used for the first iteration

2 add extra iteration prints

$<0$, same as $>0$, but add 1 more iteration after convergence

iend 1 plate 1 option

0 no plate, zero heat flux boundary, no friction at the boundary

1 plate with no power, no fins. For side plate or core barrel

2 fuel plate with power and fins -- not currently implemented.

iendn plate nplate (last plate) option, same as for iend1

ivsc $=0$, calculate viscosity and $\mathrm{k}$ for film heat trans coef at bulk coolant temp. $=1$, use clad surface $\mathrm{T}$.

niter $=$ number of iterations to get the plate power splits for an axial node consistent with the node temperatures

ilocp $=0$, each plate uses a separate random local power factor

$=1$, all plates use the same random local power factor multiplier

title (20a4)

ipwshp, ifatl, iflwnc, idf, itrprt, inom, ipronb, ibypas, ivscfl, ioptn $(9 \mathrm{i} 8,8 \mathrm{i} 1)$

ipwshp $>0$, read power shapes for plates 2 - nplate- 1 from unit ipwshp -- not yet implemented

ifatl $=0$, stop on fatal input errors. Not on comments about questionable input (repeated values for the same channel or plate)

$=1$, stop on fatal errors or comments

iflwnc $=0$, calculate flwinc on basis of gapmla(ich), only accurate

The STAT7 Code for Statistical Propagation of Uncertainties In Steady-State Thermal Hydraulics Analysis of Plate-Fueled Reactors 
if $\mathrm{nchan}=\mathrm{nplt}+1$, modeling 1 complete element.

1 , use input value for flwinc

$\mathrm{idf}=0$, use flow disparity factor $=\mathrm{df}$ as the same for all elements

$=1$, treat $\mathrm{df}$ statistically by element: average $=1.0$,

sigma $=(1.0-\mathrm{df}) / 3$

itrprt print plate power split iteration information from the

first itrprt histories.

if inom $>0$, for each nominal reactor power start with history 0 ,

nominal values for everything.

ipronb print the first ipronb histories where ONB occurs

ibypas $=1$, code calculates bypass flow and flwfac using acbyp

and dhbyp

$=0$, use input value for flwfac

ivscfl $=0$, no viscosity effect in channel flow calculation

$+\mathrm{N}$ include viscosity effects, iterate up to $\mathrm{N}$ times

$\mathrm{N}$ also print iteration results if history < iprt

ioptn $=$ options, 8 one-character integers

Note: ioptn is an array containing 8 integers, read in using $8 \mathrm{i} 1$ for a format. Thus one space is used for each number.

ioptn(1) = 0 STAT7 calculates the Carnavos heat transfer fin factor, if the finned grove depth grvdml is $>0$

ioptn(1) $>0$ for user-specified Carnavos heat transfer fin factor, if the finned grove depth grvdml is $>$ 0

Note: If grvdml $=0$, then there are no fins; and the Carnavos heat transfer fin factor $=1.0$.

$\operatorname{ioptn}(2)>0$ use equal power splits (0.5) for all nodes of all plates

$\operatorname{ioptn}(2)=0$, calculate power splits

ioptn(3) $=0$, use the STAT7 version of the Carnavos friction factor multiplier for fins

$\operatorname{ioptn}(3)=1$, Carnavos friction factor multiplier for fins $=1.0$

ioptn(3) $=2$, use the PLTEMP version of the Carnavos friction factor multiplier for fins

ioptn(4-8) reserved for future use.

Note: For ioptn(3) the STAT7 and PLTEMP treatments are the same except for in the case where there is an end channel with fins on one side and an unfinned plate on the other side.

\section{Block 2: Floating Point Variable Input Lines}

title (20a4)

thdbug, fcore, ffuel, flwfac, df, flwinc, pow0, powsgm, cnveps (9f10.5)

thdbug = turn on thermal hydraulic debug prints if thdbug $>0$.

fcore $=$ fraction of the fission power deposited in the core region (Fcore)

ffuel $=$ fuel deposition factor (Ffuel)

flwfac $=$ coolant flow factor acounts for bypass flow (Ff)

$\mathrm{df}=$ plenum flow disparity factor $(\mathrm{df})$

flwinc $=$ ratio of the average interior channel flow to the average channel

flow. Accounts for end channel flow being different from half of

interior channel flow. If all interior channels are nominally the same, then

flwinc $=\mathrm{Np} /(\mathrm{Np}-1+2 \times(\mathrm{We} / \mathrm{Wi}))$

$\mathrm{Np}=$ number of plates, $\mathrm{We}=$ end channel mass flow rate

$\mathrm{Wi}=$ interior channel mass flow rate

pow0 $=$ total power, MW. nominal value $=7.0$

powsgm $=1$ sigma fractional total power uncertainty.

cnveps $=$ ONB power iteration convergence criterion, default $=0.05$

The STAT7 Code for Statistical Propagation of Uncertainties In Steady-State Thermal Hydraulics Analysis of Plate-Fueled Reactors 
title (20a4)

plocsg, sigmax, tout, wp0, wpsgm, coolht, fl, fw,thzrml, xkzr $\quad$ (10f10.5)

plocsg = 1 sigma fractional local power uncertainty

sigmax random values limited to the range -sigmax to + sigmax, default $=5$

tout $=$ coolant outlet temperature $(\mathrm{C})=60$

$\mathrm{wp} 0=$ nominal (measured) pump flow $(\mathrm{kg} / \mathrm{s})=112.1 \mathrm{~kg} / \mathrm{s}$

wpsgm $=1$ sigma fractional pump flow uncertainty.

coolht $=$ coolant height above the top of the fuel plates $(\mathrm{m})$

$\mathrm{fl}=$ fuel length in the plate, $(\mathrm{m})$

$\mathrm{fw}=$ fuel width in the plate, $(\mathrm{m})$

thzrml = thickness of the layer $(\mathrm{Zr})$ between the fuel surface and cladding (mil)

xkzr $=$ thermal conductivity of the layer $(\mathrm{Zr})$ between the fuel surface and cladding $[\mathrm{w} /(\mathrm{m}-\mathrm{K})]$

title (20a4)

grvdml, grvwml, grvtml, gapml, gapsg, grvfav, htcsgm, epsonb, thkoxm, xkox (10f10.5)

grvdml $=$ groove depth $(\mathrm{mil})=10$. currently

grvwml $=$ groove width $($ mil $)=10$. currently

grvtml $=$ width of groove tip $(\mathrm{mil})=10$. currently

gapml $=$ fin-tip-to-fin-tip gap $(\mathrm{mil})=72$. for LEU

default value, used only if gapmli(ich) $=0$. for

ich $=2$... nchan -1

gapsg $=$ nominal gap fractional sigma, gap $=$ gapml $\left(1+x^{*}\right.$ gapsg $)$

$\mathrm{x}=$ random sampling for (val - mean)/sigma

default value, used only if gapsgi(ich) $=0$. for

ich $=2 \ldots$ nchan -1

nominal effective gap $=72+10=82 \mathrm{mil}$

if gapsg $=.0854 / 3$ and $\mathrm{x}=3$, then gap $=1.0854 * 72=78.05 \mathrm{mil}$

$(78.05+10) /(72+10)=1.0741 .074^{* *} 1.714=1.13=13 \%$

therefore gapsg $=.0854 / 3=.0285$ results in a 3 sigma flow

uncertainty $=13 \%$

alternatively, gapsg can be set based on min gap = nominal gap

4 mil

grvfav $=$ average groove gap factor $=$ average groove width/groove

width + fin width.

grvfav corresponds to grvwml/(grvwml + grvtml) for the av ch

htcsgm $=1$ sigma fractional heat transfer coef.uncertainty

epsonb $=$ iterate on power until ONB fraction = epsonb, only used if

iterpw $=1$

thkoxm $=$ thickness (mil) of the oxide layer on the plate surface

$\mathrm{xkox}=$ thermal conductivity $(\mathrm{w} / \mathrm{m}-\mathrm{K})$ of the oxide

title (20a4)

gapml0, flstrf, acbyp, dhbyp, afrv , xke, bfrv , xkf, fcarff (9f10.5)

gapml0 = nominal interior gap size, default $=$ same as gapml

flstrf $=$ fraction of channel flow in the fuel (stripe) region, .902

acbyp = bypass flow area

dhbyp = bypass hydraulic diameter

afrv friction factor $=$ afr $\times R^{* *}$ bfr. If bfrv less than 0 . then

$\mathrm{afr}=\mathrm{afrv}, \mathrm{bfr}=\mathrm{bfrv}$. Otherwise $\mathrm{afr}=.316, \mathrm{bfr}=-.25$ 
thke = effective clad thickness for conduction, one side of plate (mil)

xke $=$ clad thermal conductivity $(\mathrm{W} / \mathrm{m}-\mathrm{K})$

bfrv = see afrv above

thkf = fuel thickness, total (mil)

$\mathrm{xkf}=$ fuel thermal conductivity $(\mathrm{W} / \mathrm{m}-\mathrm{K})$

fcarff $=$ user-specified Carnavos heat transfer fin factor

\section{Block 3: Coolant Channel Gap Variable Input Lines}

Standard input format:

title (20a4)

ich, gapmli(ich), gapsgi(ich), gapmla(ich) $\quad(\mathrm{i} 8,2 \mathrm{x}, \mathrm{f} 10.2, \mathrm{f} 10.5, \mathrm{f10} 2)$

ich = coolant channel

gapmli(ich) $=$ nominal fin tip-to-fin tip gap (mil) for this element

gapsgi(ich) $=$ fractional standard deviation

gapmla(ich) = average fin tip-to-fin tip gap (mil),

average over whole core

repeat for ich $=1$ to nchan

Alternate input format:

ich1, ich2, gapmli(ich), gapsgi(ich), gapmla(ich) $(2 \mathrm{i} 4,2 \mathrm{x}, \mathrm{f} 10.2, \mathrm{f} 10.5, \mathrm{f10.2})$

sets values for ich $=$ ich1 to ich2

The two input formats can be mixed as long as all channels are included.

The default for gapmla(ich) is gapmli(ich)

\section{Block 4: Fuel and Cladding Thickness Variable Input Lines}

Standard input format:

title (20a4)

ich, thkf(ipl), thke(ipl)

ipl = plate

thkf $=$ fuel thickness (mil)

thke $=$ clad thickness (mil)

repeat for ipl $=1$ to nplate

$(\mathrm{i} 8,2 \mathrm{x}, \mathrm{f} 10.2, \mathrm{f} 10.5)$

$$
\text { nplate }=\text { nchan }+1
$$

Note: nplate includes the two extra end plates, as described under "nchan" above.

Alternate input format:

ip1, ip2, thkf(ipl), thke(ipl)

sets values for ipl = ip1 to ip2

$(2 \mathrm{i} 4, \mathrm{f} 10.2, \mathrm{f} 10.5)$

The two input formats can be mixed as long as all plates are included.

Block 5: Plate Power Distribution Variable Input Lines

title (20a4)

ipl, fstrp(ipl)

$(\mathrm{i} 8,2 \mathrm{x}, \mathrm{f} 10.2, \mathrm{f} 10.5)$

ipl = plate

fstrp = stripe power / core average stripe power

(axpow(j,ipl), j=1,nz) 
$\mathrm{j}=$ axial node

axpow $=$ axial power shape

repeat title /ipl, fstrp(ipl) / and axpow(j,ipl) for all nplate plates

Note: axpow(j,ipl) will be renormalized by the code so that for each plate the sum of axpow over all axial nodes $=1.0$. Then the nominal power (watts) in the stripe for axial node $\mathrm{j}$ of plate ipl will be $1.0 \mathrm{e}+6 \mathrm{x}$ pow $0 \mathrm{x}$ fcore $\mathrm{x}$ fstrp(ipl) $\mathrm{x}$ axpow(j,ipl)/(nelm $\mathrm{x}$ nplt $\mathrm{x}$ nstrp)

\section{Limits on number of regions}

Note that the following maximum number of regions apply:

axial nodes: 40

coolant channels: 50

plates: 51 


\section{OUTPUT VARIABLES}

Initial flwinc iteration

flwinc $=$ ratio of the average interior channel flow to the average channel flow.

Accounts for end channel flow being different from interior channel flow.

afr, bfr: friction factor $=$ afr* $\mathrm{Re}^{* *}$ bfr

Plate power split iteration

ip = plate number

plate surface 1 faces coolant channel ip - 1

plate surface 2 faces coolant channel ip

fp 1 = power split = flux at surface $1 /($ flux at surface $1+$ flux at surface 2$)$

Tfuel 1 = peak fuel temperature calculated from surface 1

Tfuel 2 = peak fuel temperature calculated from surface 2

Coolant channel results for a sample

fpowt = reactor power statistical multiplier

fflwt = pump flow multiplier

ich $=$ coolant channel

whs $=$ coolant mass flow rate $(\mathrm{kg} / \mathrm{s})$

gap = fin-tip to fin tip gap (mil)

acc $=$ coolant flow area (sq $\mathrm{m}$ )

$\mathrm{dh}=$ hydraulic diameter $(\mathrm{m})$

fcar = Carnavos fin heat transfer multiplier

$\mathrm{jz}=$ axial node

tcool $=$ coolant temperature $\left({ }^{\circ} \mathrm{C}\right)$ at bottom of the node

tcoola $=$ average coolant temperature at middle of the node

tsata $=$ saturation temperature, middle of node

reya $=$ Reynolds number, middle of node

vsca $=$ viscosity, middle of node

rhocol = coolant density, bottom of node

rhocla $=$ coolant density, node average

pcool $=$ coolant pressure $($ bar $)$ at bottom of node

pcoola $=$ coolant pressure, node average

Plate results

aclad $=$ clad surface area on the 2 surfaces

tsurf1, tsurf $2=$ clad surface temperatures on faces 1 and 2

tonb1,tonb2 = ONB temperature pn face 1 or 2

fpl1 = power split = face 1 flux / (face 1 flux + face 2 flux

powplt $=$ axial node plate power

hcool 1 , hcool 2 = film heat transfer coefficient, face 1 or face 2

fstrpw = statistical multiplier for the stripe power

tfuel 1 , tfuel2 = peak fuel temperature calculated starting from face 1 or 2

reyp1,reyp2 $=$ Re for film on face 1 or 2

vscp1, vscp2 $=$ viscosity of film on face 1 or 2

xkcp1, xkcp 2 thermal conductivity of the film on face 1 or 2

prp4p1, prp4p2 = (Prandtl number $)^{* *} 0.4$ for the film on face 1 or 2 


\section{SAMPLE INPUT}

s7n189b iend1, iendn $=1$, run in stat7n

nelm | nplt | nstrp | nz | nbatch| nsmpl | isd1 | isd2 | iprt | idbstt|

$\begin{array}{llllllllll}22 & 18 & 4 & 18 & 25 & 4000 & 21 & 3 & 2 & 1\end{array}$

nchan | iaxpow| irndmn| ipow | iterpw| iend1 | iendn | ivsc | niter | ilocp |

$\begin{array}{llllllllll}19 & 0 & 0 & 1 & 2 & 1 & 1 & 0 & 2 & 1\end{array}$

ipwshp| ifatl | iflwnc| idf | itprt | inom | ipronb| ibypas| ivscfl| ioptn |

$\begin{array}{llllll}0 & 0 & 0 & 0 & 1 & 1\end{array}$

thdbug | fcore | ffuel | flwfac | df | flwinc | pow0 | powsgm |

$\begin{array}{llllllll}0 . & .965 & .94 & .921 & .93 & .964 & 8.00 & .01667\end{array}$

plocsg | sigmax | tout | wp0 | wpsgm | coolht | fl |fw |

$\begin{array}{llllllll}.0471 & 8.0 & 60 . & 138.8 & .01667 & 3.048 & .568 & .0529\end{array}$

grvdml | grvwml | grvtml | gapml | gapsg | fdumy3 | htcsgm | epsonb |

$\begin{array}{llllllllll}10 . & 10 . & 10 . & 72.0 & .01878 & 0.0 & .0667 & .00135\end{array}$

gapml0 | flstrf | fuelthnu| fuelk nu| afrv | xke | bfrv |xkf |

$\begin{array}{llllll}72.0 & .91 & .184 & 160 . & -.2 & 14 .\end{array}$

ich | gapmli | gapsgi |

$\begin{array}{lll}1 & 50.5 & 0.1122\end{array}$

$\begin{array}{lll}2 & 72.0 & 0.0185\end{array}$

$3 \quad 72.0 \quad 0.0185$

$\begin{array}{lll}4 & 72.0 & 0.0185\end{array}$

$\begin{array}{lll}5 & 72.0 & 0.0185\end{array}$

$\begin{array}{lll}6 & 72.0 & 0.0185\end{array}$

$\begin{array}{lll}7 & 72.0 & 0.0185\end{array}$

$8 \quad 72.0 \quad 0.0185$

$972.0 \quad 0.0185$

$\begin{array}{lll}10 & 72.0 & 0.0185\end{array}$

$\begin{array}{lll}11 & 72.0 & 0.0185\end{array}$

$\begin{array}{lll}12 & 72.0 & 0.0185\end{array}$

$\begin{array}{lll}13 & 72.0 & 0.0185\end{array}$

$\begin{array}{lll}14 & 72.0 & 0.0185\end{array}$

$\begin{array}{lll}15 & 72.0 & 0.0185\end{array}$

$\begin{array}{lll}16 & 72.0 & 0.0185\end{array}$

$\begin{array}{lll}17 & 72.0 & 0.0185\end{array}$

$\begin{array}{lll}18 & 72.0 & 0.0185\end{array}$

$\begin{array}{lll}19 & 50.5 \quad 0.1122\end{array}$

iplate| thkf | thke |

$117 . \quad 17.5$

$\begin{array}{lll}2 & 20.00 \quad 15.00\end{array}$

$320.00 \quad 15.00$

$\begin{array}{lll}4 & 20.00 & 15.00\end{array}$

$\begin{array}{lll}5 & 20.00 & 15.00\end{array}$

$\begin{array}{lll}6 & 20.00 & 15.00\end{array}$

$\begin{array}{lll}7 & 20.00 & 15.00\end{array}$

$\begin{array}{lll}8 & 20.00 & 15.00\end{array}$

$920.00 \quad 15.00$

$1020.00 \quad 15.00$

$\begin{array}{lll}11 & 20.00 & 15.00\end{array}$

$\begin{array}{lll}12 & 20.00 \quad 15.00\end{array}$

$1320.00 \quad 15.00$

$1420.00 \quad 15.00$

$1520.00 \quad 15.00$

$1620.00 \quad 15.00$

$1720.00 \quad 15.00$ 


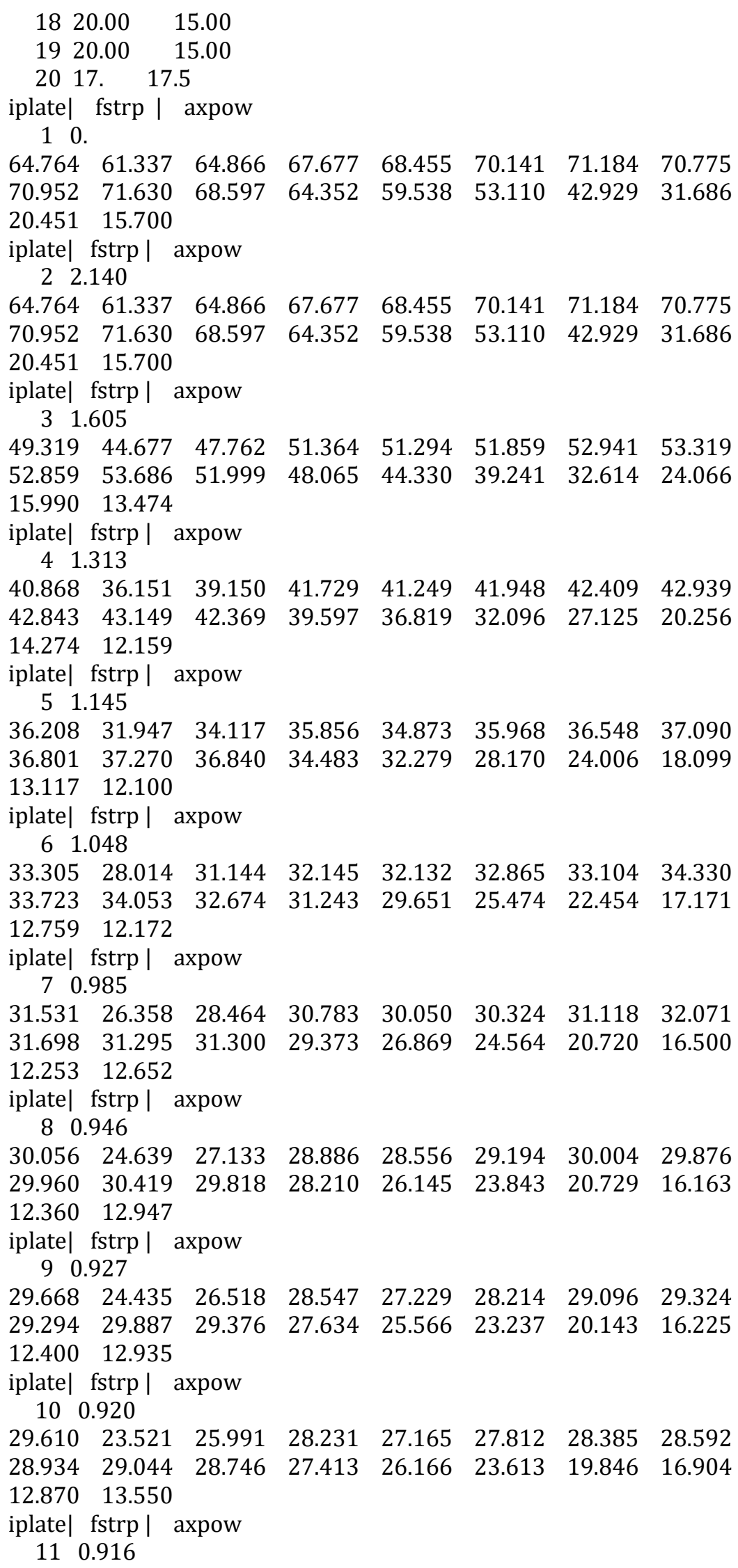




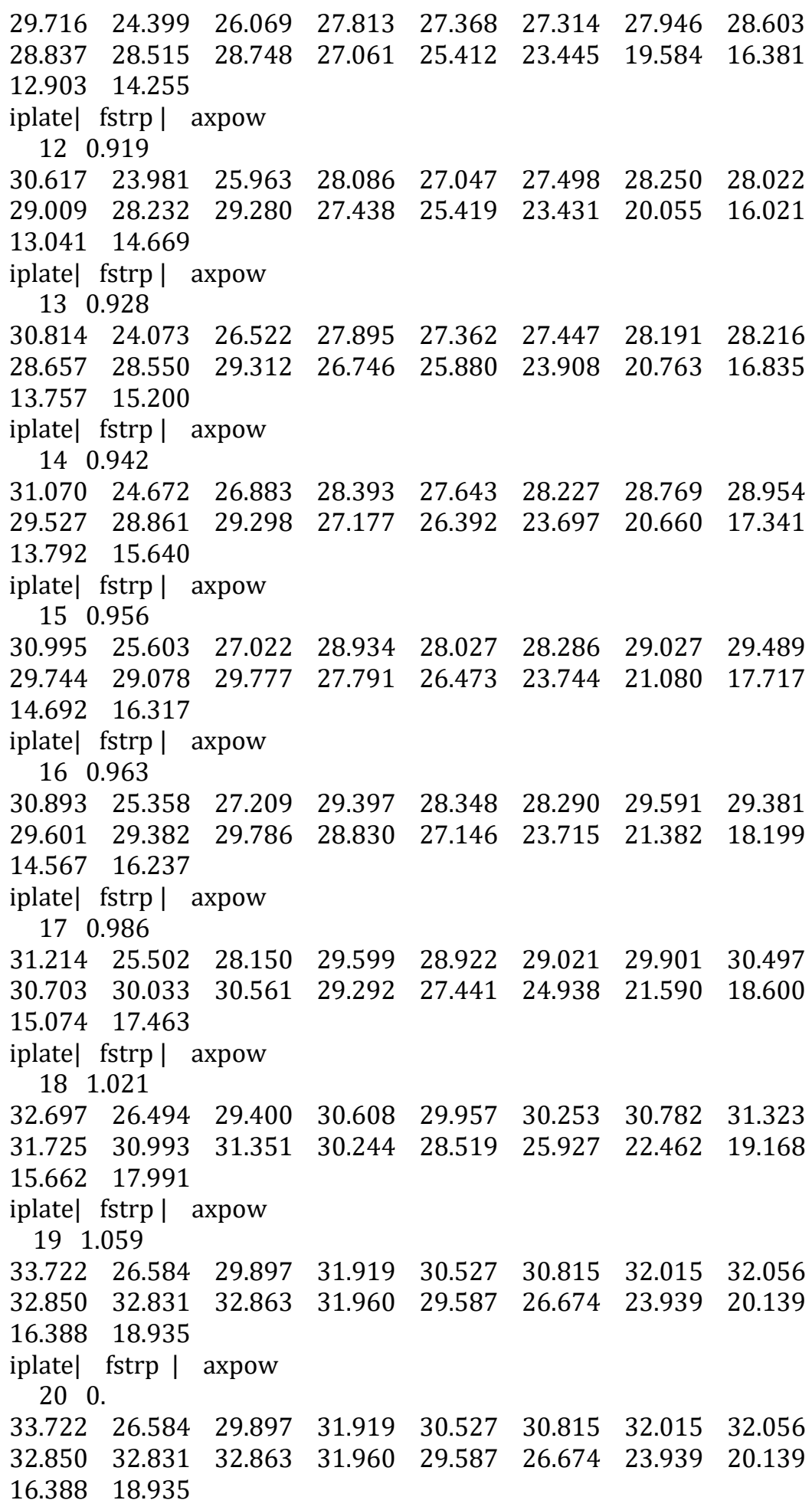




\section{REPRESENTATIVE PARTS OF A SAMPLE OUTPUT}

The output from a STAT7 run can be rather large, depending on the print options, and there is a lot of repetition for different plates, channels, histories and power iterations. Shown below are representative parts of the output from the above sample input case.

Stat7_1.0

s7n189b iend1, iendn $=1$, run in stat7n

nelm | nplt | nstrp | nz | nbatch| nsmpl | isd1 | isd2 | iprt | idbstt |

$\begin{array}{llllllllll}22 & 18 & 4 & 18 & 25 & 4000 & 21 & 3 & 2 & 1\end{array}$

nchan | iaxpow | irndmn | ipow | iterpw | iend1 | iendn | ivsc | niter | ilocp |

$\begin{array}{llllllllll}19 & 0 & 0 & 1 & 2 & 1 & 1 & 0 & 2 & 1\end{array}$

ipwshp| ifatl | iflwnc| idf | itprt | inom | ipronb| ibypas| ivscfl| ioptn |

$\begin{array}{lllllllll}0 & 0 & 0 & 0 & 1 & 1 & 0 & 0 & 000000000\end{array}$

thdbug | fcore | ffuel | flwfac | df | flwinc | pow0 | powsgm |

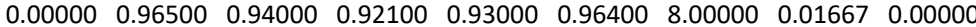

plocsg | sigmax | tout | wp0 | wpsgm | coolht | fl | fw |

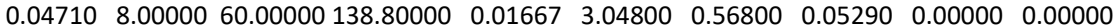

grvdml | grvwml | grvtml | gapml | gapsg | fdumy3 | htcsgm | epsonb |

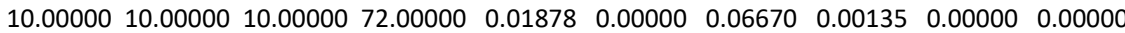

gapml0 | flstrf | fuelthnu| fuelk nu| afrv | xke | bfrv | xkf |

$\begin{array}{lllllllll}72.00000 & 0.91000 & 0.00000 & 0.00000 & 0.18400 & 160.00000 & -0.20000 & 14.00000 & 0.00000\end{array}$

ich | gapmli | gapsgi |

$\begin{array}{lllll}0 & 1 & 50.50 & 0.11220 & 0.00\end{array}$

$\begin{array}{llllll}0 & 2 & 72.00 & 0.01850 & 0.00\end{array}$

$\begin{array}{lllll}0 & 3 & 72.00 & 0.01850 & 0.00\end{array}$

$\begin{array}{llllll}0 & 4 & 72.00 & 0.01850 & 0.00\end{array}$

$\begin{array}{lllll}0 & 5 & 72.00 & 0.01850 & 0.00\end{array}$

$\begin{array}{llllll}0 & 6 & 72.00 & 0.01850 & 0.00\end{array}$

$\begin{array}{lllll}0 & 7 & 72.00 & 0.01850 & 0.00\end{array}$

$\begin{array}{llllll}0 & 8 & 72.00 & 0.01850 & 0.00\end{array}$

$\begin{array}{llllll}0 & 9 & 72.00 & 0.01850 & 0.00\end{array}$

$\begin{array}{lllll}0 & 10 & 72.00 & 0.01850 & 0.00\end{array}$

$\begin{array}{lllll}0 & 11 & 72.00 & 0.01850 & 0.00\end{array}$

$\begin{array}{lllll}0 & 12 & 72.00 & 0.01850 & 0.00\end{array}$

$\begin{array}{lllll}0 & 13 & 72.00 & 0.01850 & 0.00\end{array}$

$\begin{array}{lllll}0 & 14 & 72.00 & 0.01850 & 0.00\end{array}$

$\begin{array}{lllll}0 & 15 & 72.00 & 0.01850 & 0.00\end{array}$

$\begin{array}{lllll}0 & 16 & 72.00 & 0.01850 & 0.00\end{array}$

$\begin{array}{lllll}0 & 17 & 72.00 & 0.01850 & 0.00\end{array}$

$\begin{array}{lllll}0 & 18 & 72.00 & 0.01850 & 0.00\end{array}$

$\begin{array}{lllll}0 & 19 & 50.50 & 0.11220 & 0.00\end{array}$

after processing gapsgi and gapmli values

ich | gapmli | gapsgi |

$\begin{array}{lll}50.50 & 0.11220 & 50.50\end{array}$

$\begin{array}{lll}72.00 & 0.01850 & 72.00\end{array}$

$\begin{array}{lll}72.00 & 0.01850 & 72.00\end{array}$

$\begin{array}{lll}72.00 & 0.01850 & 72.00\end{array}$

$\begin{array}{lll}72.00 & 0.01850 & 72.00\end{array}$

$\begin{array}{lll}72.00 & 0.01850 & 72.00\end{array}$

$\begin{array}{lll}72.00 & 0.01850 & 72.00\end{array}$

$\begin{array}{lll}72.00 & 0.01850 & 72.00\end{array}$

$\begin{array}{lll}72.00 & 0.01850 & 72.00\end{array}$

$\begin{array}{lll}72.00 & 0.01850 & 72.00\end{array}$

$\begin{array}{lll}72.00 & 0.01850 & 72.00\end{array}$

$\begin{array}{lll}72.00 & 0.01850 & 72.00\end{array}$

$\begin{array}{llll}72.00 & 0.01850 & 72.00\end{array}$

iplate| fstrp | axpow

10.0000

64.7640061 .3370064 .8660067 .6770068 .4550070 .1410071 .1840070 .77500

70.9520071 .6300068 .5970064 .3520059 .5380053 .1100042 .9290031 .68600

20.4510015 .70000

The STAT7 Code for Statistical Propagation of Uncertainties In Steady-State Thermal Hydraulics Analysis of Plate-Fueled Reactors 
renormalized axial power

$\begin{array}{llllllll}0.06238 & 0.05908 & 0.06248 & 0.06519 & 0.06594 & 0.06756 & 0.06857 & 0.06817\end{array}$ $\begin{array}{llllllll}0.06835 & 0.06900 & 0.06608 & 0.06199 & 0.05735 & 0.05116 & 0.04135 & 0.03052\end{array}$

0.019700 .01512

iplate| fstrp| axpow

$2 \quad 2.1400$

64.7640061 .3370064 .8660067 .6770068 .4550070 .1410071 .1840070 .77500

$70.9520071 .6300068 .5970064 .3520059 .53800 \quad 53.1100042 .9290031 .68600$

20.4510015 .70000

renormalized axial power

$\begin{array}{llllllll}0.06238 & 0.05908 & 0.06248 & 0.06519 & 0.06594 & 0.06756 & 0.06857 & 0.06817\end{array}$

$\begin{array}{llllllll}0.06835 & 0.06900 & 0.06608 & 0.06199 & 0.05735 & 0.05116 & 0.04135 & 0.03052\end{array}$

0.019700 .01512

thermal hydraulic results for sample 0

pow $0=8.0000$ fpowt $=1.0000, \mathrm{fflwt}=1.0000$ ONB occurred at 0 places

ich $=1$ whs $=4.286 \mathrm{E}-02$. gap $=5.050 \mathrm{E}+01 \mathrm{acc}=1.864 \mathrm{E}-05 \mathrm{dh}=1.880 \mathrm{E}-03$

fcar $=0.714$, Carnavos friction factor multiplier 1.044

jz tcool tcoola tsata reya vsca rhocol rhocla pcool pcoola cpa

146.7047 .60113 .37 7.590E+03 5.694E-04 9.895E+02 9.892E+02 1.611E+05 1.603E+05 4.180E+03

$248.5049 .35113 .04 \quad 7.820 \mathrm{E}+03 \quad 5.526 \mathrm{E}-04 \quad 9.888 \mathrm{E}+02 \quad 9.884 \mathrm{E}+02 \quad 1.594 \mathrm{E}+05 \quad 1.585 \mathrm{E}+05 \quad 4.180 \mathrm{E}+03$

350.2151 .11112 .71 8.054E+03 5.366E-04 9.880E+02 9.876E+02 1.576E+05 1.568E+05 4.181E+03

452.0152 .96112 .37 8.302E+03 5.205E-04 9.872E+02 9.867E+02 1.559E+05 1.550E+05 4.182E+03

$553.9054 .86112 .03 \quad 8.560 \mathrm{E}+03 \quad 5.048 \mathrm{E}-04 \quad 9.863 \mathrm{E}+02$ 9.858E+02 1.542E+05 1.533E+05 4.182E+03

655.8256 .80111 .69 8.825E+03 4.897E-04 9.854E+02 9.849E+02 1.524E+05 1.516E+05 4.183E+03

757.7858 .78111 .35 9.099E+03 4.749E-04 9.844E+02 9.839E+02 1.507E+05 1.499E+05 4.184E+03 $859.7860 .77111 .019 .377 \mathrm{E}+03 \quad 4.609 \mathrm{E}-04$ 9.834E+02 9.828E+02 1.490E+05 1.482E+05 4.185E+03

$961.7662 .76110 .679 .658 \mathrm{E}+03 \quad 4.475 \mathrm{E}-04 \quad 9.823 \mathrm{E}+02 \quad 9.818 \mathrm{E}+02 \quad 1.473 \mathrm{E}+05 \quad 1.465 \mathrm{E}+05 \quad 4.186 \mathrm{E}+03$ $1063.7664 .77110 .329 .943 \mathrm{E}+03$ 4.346E-04 9.813E+02 9.807E+02 1.456E+05 1.448E+05 4.187E+03 1165.7866 .75109 .97 1.023E+04 4.226E-04 9.802E+02 9.796E+02 1.439E+05 1.431E+05 4.188E+03 1267.7268 .63109 .62 1.050E+04 4.117E-04 9.791E+02 9.786E+02 1.423E+05 1.414E+05 4.189E+03 1369.5470 .38 109.27 1.075E+04 4.019E-04 9.781E+02 9.776E+02 1.406E+05 1.397E+05 4.190E+03 1471.2371 .99108 .91 1.099E+04 3.933E-04 9.771E+02 9.767E+02 1.389E+05 1.381E+05 4.191E+03 1572.7473 .36108 .55 1.119E+04 3.861E-04 9.762E+02 9.758E+02 1.372E+05 1.364E+05 4.192E+03 $1673.9874 .44108 .191 .135 \mathrm{E}+04 \quad 3.807 \mathrm{E}-04 \quad 9.755 \mathrm{E}+02 \quad 9.752 \mathrm{E}+02 \quad 1.356 \mathrm{E}+05 \quad 1.348 \mathrm{E}+05 \quad 4.193 \mathrm{E}+03$ 1774.9075 .21 107.83 1.147E+04 3.769E-04 9.749E+02 9.747E+02 1.339E+05 1.331E+05 4.193E+03 1875.5275 .76107 .46 1.155E+04 3.742E-04 9.746E+02 9.744E+02 1.323E+05 1.315E+05 4.194E+03 $1976.00 \quad 9.743 \mathrm{E}+02 \quad 1.306 \mathrm{E}+05$

ich $=2$ whs $=6.727 \mathrm{E}-02$. gap $=7.200 \mathrm{E}+01 \mathrm{acc}=2.755 \mathrm{E}-05 \mathrm{dh}=2.083 \mathrm{E}-03$

fcar $=0.716$, Carnavos friction factor multiplier 1.059

jz tcool tcoola tsata reya vsca rhocol rhocla pcool pcoola cpa

146.7047 .72113 .36 8.953E+03 5.682E-04 9.895E+02 9.891E+02 1.611E+05 1.602E+05 4.180E+03

$248.7549 .69113 .039 .259 \mathrm{E}+03 \quad 5.494 \mathrm{E}-049.887 \mathrm{E}+02 \quad 9.882 \mathrm{E}+02 \quad 1.593 \mathrm{E}+05 \quad 1.584 \mathrm{E}+05 \quad 4.181 \mathrm{E}+03$

$350.6451 .64112 .699 .565 \mathrm{E}+03 \quad 5.318 \mathrm{E}-04$ 9.878E+02 9.873E+02 1.576E+05 1.567E+05 4.181E+03

$452.6453 .70112 .369 .891 \mathrm{E}+03 \quad 5.143 \mathrm{E}-049.869 \mathrm{E}+02 \quad 9.864 \mathrm{E}+02 \quad 1.558 \mathrm{E}+05 \quad 1.550 \mathrm{E}+05 \quad 4.182 \mathrm{E}+03$

$554.7655 .82112 .021 .023 \mathrm{E}+04$ 4.972E-04 9.859E+02 9.853E+02 1.541E+05 1.532E+05 4.183E+03

656.8857 .95111 .68 1.058E+04 4.810E-04 9.848E+02 9.843E+02 1.524E+05 1.515E+05 4.184E+03

759.0360 .11111 .34 1.093E+04 4.654E-04 9.837E+02 9.832E+02 1.507E+05 1.498E+05 4.185E+03 $861.2062 .29111 .001 .129 \mathrm{E}+04$ 4.506E-04 9.826E+02 9.820E+02 1.490E+05 1.481E+05 4.186E+03

$963.3764 .45110 .651 .165 \mathrm{E}+04$ 4.366E-04 9.815E+02 9.809E+02 1.473E+05 1.464E+05 4.187E+03 1065.5366 .62110 .31 1.202E+04 4.233E-04 9.803E+02 9.797E+02 1.456E+05 1.447E+05 4.188E+03 $1167.7168 .75109 .961 .238 \mathrm{E}+04$ 4.110E-04 9.791E+02 9.785E+02 1.439E+05 1.431E+05 4.189E+03 1269.7970 .75 109.61 1.272E+04 3.999E-04 9.779E+02 9.774E+02 1.422E+05 1.414E+05 4.190E+03 1371.7172 .60109 .26 1.304E+04 3.901E-04 9.768E+02 9.763E+02 1.405E+05 1.397E+05 4.192E+03 $1473.4874 .26108 .911 .333 \mathrm{E}+04 \quad 3.816 \mathrm{E}-04 \quad 9.758 \mathrm{E}+02 \quad 9.753 \mathrm{E}+02 \quad 1.389 \mathrm{E}+05$ 1.381E+05 4.193E+03 1575.0375 .65108 .55 1.358E+04 3.747E-04 9.749E+02 9.745E+02 1.372E+05 1.364E+05 4.194E+03 $1676.2876 .72108 .191 .376 \mathrm{E}+04$ 3.696E-04 9.741E+02 9.738E+02 1.356E+05 1.347E+05 4.194E+03 $1777.1677 .43107 .831 .389 \mathrm{E}+04$ 3.663E-04 9.736E+02 9.734E+02 1.339E+05 1.331E+05 4.195E+03 1877.7077 .91107 .46 1.397E+04 3.641E-04 9.732E+02 9.731E+02 1.323E+05 1.315E+05 4.195E+03 $1978.11 \quad 9.730 \mathrm{E}+02 \quad 1.306 \mathrm{E}+05$

The STAT7 Code for Statistical Propagation of Uncertainties In Steady-State Thermal Hydraulics Analysis of Plate-Fueled Reactors 
plate 2 , aclad $=8.346 \mathrm{E}-048.346 \mathrm{E}-04$

jz Tcoola Tsata Tonb Tsurf1 Tox-cd Tcd-zr Tzr-f Tfmax1 Tfmax2 Tf-zr Tzr-cd Tcd-ox Tsurf2 Tonb Tsata Tcoola2 fp1 $147.60113 .37119 .9677 .8177 .8179 .5479 .5486 .0686 .0679 .2979 .2977 .5377 .53120 .00113 .3647 .72 \quad 0.495$

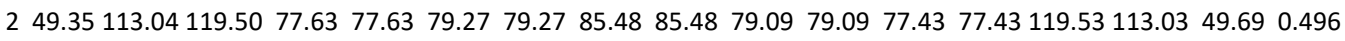

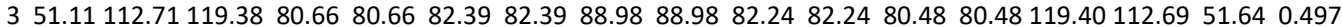

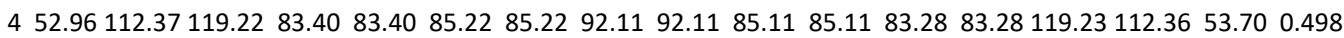

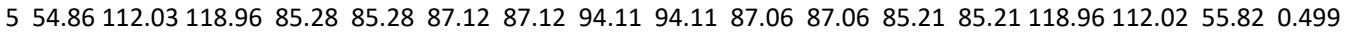

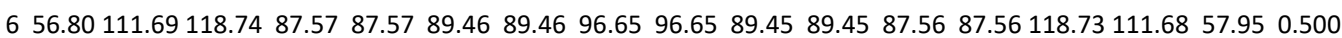
758.78111 .35118 .4989 .6289 .6291 .5491 .5498 .8698 .8691 .5791 .5789 .6689 .66118 .48111 .3460 .110 .501 860.77111 .01118 .1891 .0791 .0792 .9892 .98100 .29100 .2993 .0793 .0791 .1791 .17118 .15111 .0062 .290 .502 962.76110 .67117 .8992 .7792 .7794 .6994 .69102 .05102 .0594 .8394 .8392 .9392 .93117 .84110 .6564 .450 .502 1064.77110 .32117 .6294 .7094 .7096 .6596 .65104 .09104 .0996 .8396 .8394 .9294 .92117 .57110 .3166 .620 .503 $1166.75109 .97117 .1795 .1295 .1296 .9896 .98104 .15104 .1597 .23 \quad 97.2395 .4095 .40117 .10109 .96 \quad 68.75 \quad 0.504$ 1268.63109 .62116 .6695 .0095 .0096 .7696 .76103 .52103 .5297 .0897 .0895 .3695 .36116 .57109 .6170 .750 .506 1370.38109 .27116 .1194 .6094 .6096 .2396 .23102 .53102 .5396 .6196 .6195 .0395 .03116 .00109 .2672 .600 .508 1471.99108 .91115 .4593 .4793 .4794 .9394 .93100 .61100 .6195 .3795 .3793 .9793 .97115 .32108 .9174 .260 .510 1573.36108 .55114 .5390 .7390 .7391 .9291 .9296 .5996 .5992 .4492 .4491 .3191 .31114 .37108 .5575 .650 .515

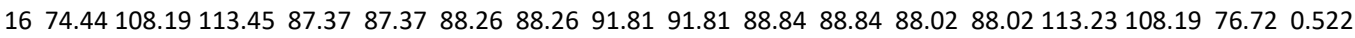

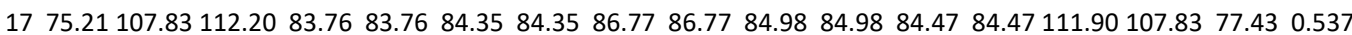

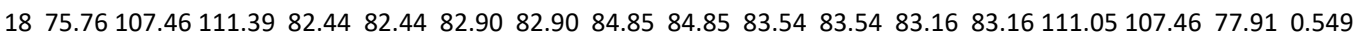
jz reyp1 reyp2 vscp1 vscp2 xkcp1 xkcp2 prp4p1 prp4p2 hcool1 hcool2 qc1 qc2

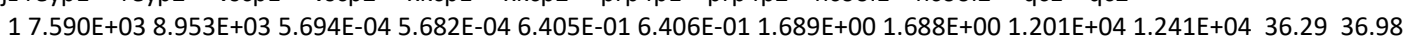
2 7.821E+03 9.259E+03 5.526E-04 5.494E-04 6.426E-01 6.430E-01 1.667E+00 1.663E+00 1.218E+04 1.260E+04 34.45 34.95 3 8.054E+03 9.565E+03 5.365E-04 5.318E-04 6.447E-01 6.453E-01 1.645E+00 1.639E+00 1.235E+04 1.280E+04 36.49 36.91 4 8.302E+03 9.891E+03 5.205E-04 5.143E-04 6.468E-01 6.476E-01 1.623E+00 1.615E+00 1.253E+04 1.300E+04 38.13 38.44 5 8.560E+03 1.023E+04 5.048E-04 4.972E-04 6.489E-01 6.499E-01 1.602E+00 1.591E+00 1.271E+04 1.320E+04 38.65 38.81 6 8.825E+03 1.058E+04 4.897E-04 4.810E-04 6.510E-01 6.521E-01 1.580E+00 1.568E+00 1.289E+04 1.341E+04 39.66 39.70 7 9.099E+03 1.093E+04 4.749E-04 4.654E-04 6.530E-01 6.543E-01 1.560E+00 1.546E+00 1.307E+04 1.362E+04 40.32 40.23 8 9.377E+03 1.129E+04 4.609E-04 4.506E-04 6.550E-01 6.564E-01 1.539E+00 1.524E+00 1.326E+04 1.382E+04 40.16 39.92 9 9.658E+03 1.165E+04 4.475E-04 4.366E-04 6.568E-01 6.584E-01 1.520E+00 1.504E+00 1.344E+04 1.403E+04 40.33 39.95 $109.943 \mathrm{E}+03$ 1.202E+04 4.346E-04 4.233E-04 6.587E-01 6.603E-01 1.501E+00 1.484E+00 1.362E+04 1.423E+04 40.78 40.27 11 1.023E+04 1.238E+04 4.226E-04 4.110E-04 6.604E-01 6.621E-01 1.483E+00 1.465E+00 1.380E+04 1.443E+04 39.16 38.46 12 1.050E+04 1.272E+04 4.117E-04 3.999E-04 6.620E-01 6.637E-01 1.466E+00 1.448E+00 1.397E+04 1.461E+04 36.85 35.96 13 1.075E+04 1.304E+04 4.019E-04 3.901E-04 6.634E-01 6.651E-01 1.452E+00 1.433E+00 1.413E+04 1.478E+04 34.2133.16 14 1.099E+04 1.333E+04 3.933E-04 3.816E-04 6.646E-01 6.663E-01 1.438E+00 1.420E+00 1.427E+04 1.493E+04 30.66 29.44 15 1.119E+04 1.358E+04 3.861E-04 3.747E-04 6.656E-01 6.673E-01 1.427E+00 1.409E+00 1.439E+04 1.506E+04 25.00 23.58 16 1.135E+04 1.376E+04 3.807E-04 3.696E-04 6.664E-01 6.680E-01 1.419E+00 1.401E+00 1.448E+04 1.515E+04 18.72 17.13

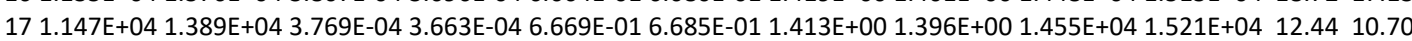
18 1.155E+04 1.397E+04 3.742E-04 3.641E-04 6.673E-01 6.688E-01 1.408E+00 1.392E+00 1.460E+04 1.526E+04 9.75 8.01

\footnotetext{
Results for 25 batches with 4000 samples per batch ONB occured in at least one axail node in 136 samples, giving an ONB fraction $=1.360 \mathrm{E}-03$ sigma $=9.704 \mathrm{E}-05$ for sqrt(variance), or sigma $=1.166 \mathrm{E}-04$ for $\operatorname{sqrt}(\mathrm{N})$ nominal power $=9.28340$ peak ONBR at node 13 on surface 1 of plate 2 ONBR $=1.320 \mathrm{E}-03$
}

computer time for thermal hydraulics and sampling $=1.187 \mathrm{E}+01$ seconds computer time for statistical analysis $=6.104 \mathrm{E}-05$

\author{
power iteration table \\ iteration power ONB fraction sigma ONB fraction - criterion \\ 18.0000 5.000E-05 2.000E-05-3.296E+00 \\ 29.0000 8.000E-04 6.633E-05-5.232E-01 \\ $3 \quad 10.0000$ 6.740E-03 2.012E-04 1.608E+00 \\ $4 \quad 9.2455$ 1.240E-03 9.642E-05-8.499E-02 \\ $5 \quad 9.2834$ 1.360E-03 9.704E-05 7.380E-03 \\ ilow $=4$, vallow $=-8.499 \mathrm{E}-02$, ihigh $=3$, valhgh $=1.608 \mathrm{E}+00$
}

power converged at iteration 5, power $=9.2834, \mathrm{ONB}$ fraction $=1.360 \mathrm{E}-03$, sigma $=9.704 \mathrm{E}-05$

limiting: power $=9.2834 \mathrm{Mw}$, surface 1 , fuel plate 1 , axial node 13 


\section{FORTRAN CODING}

With one exception the STAT code is written using the FORTRAN 77 standard (X3.9-1978) of the American National Standards Institute (ANSI), which is a subset of FORTRAN 90. The one exception is that the STAT code is written with lower case letters, which is allowed in FORTRAN 90. The FORTRAN 77 standard calls for upper case letters for all coding. 


\section{COMPILING AND EXECUTING THE CODE}

The command used to compile the STAT7 code with the ifort compiler is:

ifort source.f

mv a.out executable

The command used to execute the code in Unix or Linux is:

executable $<$ input $>$ output

or

./ executable < input $>$ output 


\section{ACKNOWLEDGEMENTS}

The authors express their gratitude to the staff of the MIT Nuclear Reactor Laboratory with whom this code was conceived. In particular the Master's degree work of Keng-Yen Chiang provided the initial methodology to begin this effort which was continued in a collaboration between MIT and Argonne staff. Floyd Dunn, who authored this software, is gratefully acknowledged. Though no longer active at Argonne, his contributions have remained the basis for the current software. This work was sponsored by the U.S. Department of Energy, Office of Material Management and Minimization in the U.S. National Nuclear Security Administration Office of Defense Nuclear Nonproliferation under Contract DE-AC02-06CH11357. 


\section{REFERENCES}

1. A. J. Dave, K. Sun, L. Hu, S. H. Pham, E. H. Wilson, D. Jaluvka, “ Thermal-hydraulic analyses of MIT reactor LEU transition cycles”, Progress in Nuclear Energy, 118, January 2020.

2. The RELAP5-3D(C Code Development Team, RELAP5-3D(C Code Manual, Version 2.3, INEELEXT-98-00834, Idaho National Laboratory, April 2005.

3. K-Y. Chiang, L.-W Hu, B. Forget, "Evaluation of Thermal Hydraulic Limits Based on Statistical Propagation of Parametric Uncertainties”, RERTR 2011, Santiago, Chile, October 2011.

4. NIST/SEMATECH e-Handbook of Statistical Methods, http://www.itl.nist.gov/div898/handbook/

5. James H. Rust, "Nuclear Power Plant Engineering", Haralson Publishing Company, P.O. Box 20366, Atlanta, Georgia 30325, 1979

6. Y. Sudo et al., "Experimental Study of Incipient Nucleate Boiling in Narrow Vertical Rectangular Channel Simulating Subchannel of Upgraded JRR-3", J. of Nuclear Science and Technology, 23[1], Jan. 1986.

7. T.C. Carnavos, "Heat Transfer Performance of Internally Finned Tubes in Turbulent Flow," Heat Transfer Engineering, 1: 4, 32-37, 1980

8. Marvin Zelen and Norman C. Severo, Handbook of Mathematical Functions, pp. 931-933, Milton Abramowitz and Irene A. Stegun, editors, Dover Publications, New York (1965)

9. K-Y. Chiang, "Thermal Hydraulic Limits Analysis for the MIT Research Reactor Low Enrichment Uranium Core Conversion Using Statistical Propagation of Parametric Uncertainties”, Master Thesis, Massachusetts Institute of Technology, 2009 


\section{APPENDIX A: COMMENTS ON FINS}

Fins can be used to improve the heat transfer performance of a device by increasing the heat transfer area. The current MITR HEU core uses fins on the fuel plates. The fins are 10 mils high, 10 mils wide, and they are 10 mils apart. These fins double the heat transfer area of the fuel plates. The fins also increase the friction pressure drop in the fuel elements.

The Carnavos treatment is used in STAT7 to account for fins. Carnavos made pressure drop measurements and heat transfer coefficient measurements involving coolant flow inside circular tubes, with fins on the inside of the tube wall. The results of the measurements are correlated in terms of ratios of surface areas and flow areas. The implementation of these correlations in STAT7 is described in Sections 5.1 and 5.2.

There are two issues with using the Carnavos fin correlations for RERTR applications. The first is that the Carnavos measurements were made in circular geometry tubes, whereas the coolant channels we are interested in are rectangular. The second issue is that the measurements were made in a geometry with fins all of the way around the outside of the coolant channels, which may be similar to an interior rectangular channel with fins on both long sides; but we are also interested in end channels with fins on only one side. Carnavos did not make any measurements with fins only part way around the tubes. The analogy with the use of the hydraulic diameter, $D_{h}=4 \mathrm{x}$ the flow area/the wetted perimeter, suggests that the measurement geometry issues mentioned above can be overcome. For turbulent flow, the hydraulic diameter can be used to calculate reasonably accurate pressure drops for almost any geometry. A similar situation may exist for the use by Carnavos of the ratio of the actual free flow area to the nominal flow area without the fins to correlate a fin friction factor multiplier. The Carnavos experiments are the best available results that address the fin effects.

The Carnavos fin treatment is also used in the PLTEMP code ${ }^{\mathrm{A} 1}$. The PLTEMP fin treatment is the same as that in STAT7, except for the friction factor multiplier for an end channel with fins on one side and no fins on the other side. For this case, STAT7 uses a straight-forward application of the Carnavos correlation, whereas PLTEMP uses a weighted average of a finned friction factor and a no-fin friction factor. PLTEMP uses

$$
f_{\text {avg }}=\left(f_{\text {fin }} W_{\text {fin }}+f_{\text {nofin }} W_{\text {nofin }}\right) /\left(w_{\text {fin }}+w_{\text {nofin }}\right)
$$

where $f_{\text {fin }}$ and $f_{\text {nofin }}$ are the finned and no-fin friction factors, and $w_{\text {fin }}$ and $w_{\text {nofin }}$ are the wetted perimeters of the finned and no-fin surfaces. There is no experimental data to determine whether the STAT7 treatment or the PLTEMP treatment is more accurate for an end channel with fins on one side. There is an option in STAT7 to use either the STAT7 fin treatment or the PLTEMP treatment, so for a particular case it is possible to find out how much difference it makes.

In order to determine the impact of the fin treatment for a case of interest, STAT7 runs were made for case 189 from Reference A2 using various fin treatment options. This case is a LEU case with fins the same as the fins in current HEU core: 10 mil wide x 10 mil high x 10 mil between fins. In this case channel 1 is the limiting channel. Channel 1 is an end channel, and channel 2 is the first interior channel. The results of these runs are listed in Table A1. 
Table A.1. STAT7 Results for Various Fin Treatment Options

\begin{tabular}{|c|c|c|c|c|c|c|c|c|c|c|}
\hline & $\begin{array}{l}\text { Limitin } \\
\text { g power } \\
\text { (MW) }\end{array}$ & Coola & $\begin{array}{l}\text { flow } \\
\text { (s) }\end{array}$ & $\begin{array}{r}\text { fric } \\
\text { fac } \\
\text { mult }\end{array}$ & $\begin{array}{l}\text { ion } \\
\text { or } \\
\text { plier }\end{array}$ & $\begin{array}{r}\text { heat } \\
\text { mul }\end{array}$ & $\begin{array}{l}\text { Insfer } \\
\text { lier }\end{array}$ & $\begin{array}{c}\text { Pressure } \\
\text { drop } \\
\text { (kPa) }\end{array}$ & $D_{h}$ & \\
\hline channel & & 1 & 2 & 1 & 2 & 1 & 2 & & 1 & 2 \\
\hline No fins ${ }^{\mathrm{a}}$ & 5.9307 & .03555 & .06813 & --- & --- & 1.0 & 1.0 & 16.0 & .2819 & .4166 \\
\hline $\begin{array}{l}\text { Fins, } \\
\text { friction } \\
\text { factor } \\
\text { multiplier } \\
=1.0\end{array}$ & 9.2786 & .04255 & .06731 & 1.0 & 1.0 & .714 & .716 & 29.1 & .1880 & .2083 \\
\hline $\begin{array}{l}\text { Fins, } \\
\text { STAT7 } \\
\text { friction } \\
\text { factor } \\
\text { multiplier }\end{array}$ & 9.2834 & .04286 & .06727 & 1.044 & 1.059 & .714 & .716 & 30.5 & .1880 & .2083 \\
\hline $\begin{array}{l}\text { Fins, } \\
\text { PLTEMP } \\
\text { friction } \\
\text { factor } \\
\text { multiplier }\end{array}$ & 9.3410 & .04318 & .06724 & 1.029 & 1.059 & .714 & .716 & 30.4 & .1880 & .2083 \\
\hline
\end{tabular}

a The channel gap sizes in the no-fins case were adjusted to give the same coolant flow areas as in the cases with fins.

The impact of the Carnavos fin treatment is mainly due to the heat transfer multiplier rather than the friction factor multiplier. For this case, the heat transfer multiplier has about a $30 \%$ impact on the heat transfer, whereas the friction factor multiplier has a $3-6 \%$ impact on the friction factor and less than $1 \%$ on the limiting power.

For this case the fins double the heat transfer surface area, although the Carnavos heat transfer multiplier of $.714-.716$ reduces the overall improvement in the clad-to-coolant heat transfer. Also, the heat transfer coefficient is proportional to $1 / \mathrm{D}_{\mathrm{h}}{ }^{0.2}$, and this improves the heat transfer coefficient by $8-15 \%$. The net heat transfer is improved by a factor of about 1.5 by adding the fins.

The impact on the pressure drop caused by adding fins is mostly caused by the change in hydraulic diameter due to the change in wetted perimeter. The friction factor multiplier is a small shape factor correction to account for effects not captured by the change in wetted perimeter.

The differences in limiting power or pressure drop between using the STAT7 friction factor multiplier and using the PLTEMP friction factor multiplier are less than 1\%. Carnavos states that his measured data points for pressure drop and for temperature drop from the clad surface to the bulk liquid fall between $\pm 10 \%$ from the correlations, so $1 \%$ differences are well within the accuracy of the correlations. 


\section{REFERENCES}

A1. A. P. Olson and Kalimullah, "A User's Guide to the PLTEMP/ANL CODE", ANL/RERTR/TM-11-22 Rev 2 Version 4.2_r80-160725, Argonne National Laboratory, July 25, 2016.

A2. A. Bergeron, E.H. Wilson, G. Yesilyurt, F. E. Dunn, J.G. Stevens, L. Hu and T.H. Newton Jr. , "Low Enriched Uranium Core Design for the Massachusetts Institute of Technology Reactor (MITR) with Un-finned 12 mil-thick Clad UMo Monolithic Fuel", ANL/GTRI/TM-13/15, Argonne National Laboratory, November 2013. 


\section{Argonne $\mathbf{A}$}

Nuclear Science \& Engineering Division

Argonne National Laboratory

9700 South Cass Avenue, Bldg. 208

Argonne, IL 60439

www.anl.gov

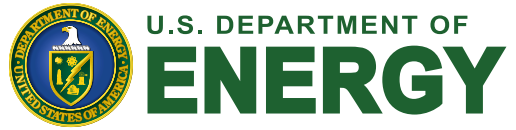

Argonne National Laboratory is a U.S. Department of Energy laboratory managed by UChicago Argonne, LLC 